OPEN ACCESS

Edited by:

Orazio Vittorio,

University of New South

Wales, Australia

Reviewed by:

Clara Mattu,

Politecnico di Torino, Italy

Shiyong Song,

Henan University, China

*Correspondence:

Jingxin Mo

jingxin.mo@hotmail.com

tThese authors have contributed equally to this work

Specialty section:

This article was submitted to

Nanobiotechnology,

a section of the journal

Frontiers in Bioengineering and

Biotechnology

Received: 01 July 2019 Accepted: 11 September 2019

Published: 01 October 2019

Citation:

Li M, Mao L, Chen M, Li M, Wang K and Mo J (2019) Characterization of an Amphiphilic Phosphonated Calixarene Carrier Loaded With Carboplatin and Paclitaxel: A Preliminary Study to Treat Colon

Cancer in vitro and in vivo. Front. Bioeng. Biotechnol. 7:238.

doi: 10.3389/fbioe.2019.00238

\section{Characterization of an Amphiphilic Phosphonated Calixarene Carrier Loaded With Carboplatin and Paclitaxel: A Preliminary Study to Treat Colon Cancer in vitro and in vivo}

\author{
Meiying $\mathrm{Li}^{1,2 \dagger}$, Liujun $\mathrm{Mao}^{3+}$, Meirong Chen ${ }^{4}$, Mingxin $\mathrm{Li}^{2}$, Kaixuan $\mathrm{Wang}^{2}$ and Jingxin $\mathrm{Mo}^{1 \star}$ \\ ${ }^{1}$ Clinical Research Center for Neurological Diseases of Guangxi Province, Affiliated Hospital of Guilin Medical University, \\ Guilin, China, ${ }^{2}$ School of Pharmacy, Guilin Medical University, Guilin, China, ${ }^{3}$ Department of Further-Education, Affiliated \\ Hospital of Guilin Medical University, Guilin, China, ${ }^{4}$ Department of Graduate, Affiliated Hospital of Guilin Medical University, \\ Guilin, China
}

The inadequacy of available detection methods and a naturally aggressive progression have made colon cancer the third most common type of cancer, accounting for 10\% of all cancer cases. The heterogeneity and genomic instability of colon cancer tumors make current treatments unsatisfactory. This study evaluated a novel nanoscale delivery platform comprising phosphonated calixarenes (P4C6) co-loaded with paclitaxel (PTX) and carboplatin (CPT). The nanoparticles showed average hydrodynamic sizes of 84 $\pm 8 \mathrm{~nm}$ for empty P4C6 nanoparticle and $119 \pm 13 \mathrm{~nm}$ for PTX-CPT-P4C6. The corresponding zeta potentials were $-40.8 \pm 8.8$ and $-35.4 \pm 4.2 \mathrm{mV}$. The optimal CPT:PTX ratio was 5.22:1, and PTX-CPT-P4C6 with this ratio was more cytotoxic against HT-29 cells than against Caco- 2 cells $\left(\mathrm{IC}_{50}, 0.4 \pm 0.02\right.$ vs. $\left.2.1 \pm 0.3 \mu \mathrm{M}\right)$, and it induced higher apoptosis in HT-29 cells (56.6 \pm 4.5 vs. $44.9 \pm 3.44 \%$ ). PTX-CPT-P4C6 inhibited the invasion and migration of HT-29 cells more strongly than the free drugs. It also inhibited the growth of HT-29 tumors in mice to the greatest extent of all formulations, with negligible side effects. This research demonstrates the potential of P4C6 to deliver two chemotherapeutic agents to colon cancer tumors to provide synergistic efficacy than single drug administration.

Keywords: phosphonated calixarene, paclitaxel, carboplatin, nanomedicine, colon cancer

\section{INTRODUCTION}

Colorectal cancer (colon cancer) is the third most common type of cancer worldwide and a leading cause of cancer death, making up about $10 \%$ of all cancer cases (den Bakker et al., 2018). In 2012, its global mortality rate was estimated at more than 600,000 per year, and its incidence has increased over the last 25 years (Yodkeeree et al., 2009). Colon cancer manifests as the formation of adenomatous polyps and malignant cells in the colon (Basu et al., 2018). Its naturally aggressive progression, in combination with a lack of accurate screening and detection methods, means that 
patients are typically diagnosed at advanced stages, and they therefore respond inadequately to available treatments (Blind et al., 2018). Chemotherapies are essential due to the high risk of relapse after surgery, yet most drugs for treating advancedstage colorectal cancer, such as cisplatin, are relatively ineffective and frequently induce adverse side effects (Rabik and Dolan, 2007; Robella et al., 2019), such as nephro-(Zhu et al., 2019), hepato-(Zhang X. et al., 2019), and cardiotoxicity (Dasari and Tchounwou, 2014). These considerations highlight the need for new therapeutic approaches for this disease.

Nanomedicine is an emerging, dynamic branch of therapeutics that continues to gain prominence as a viable treatment alternative for many cancers, including colon cancer (Zhang Q. et al., 2019). Nanomedicine encompasses the application of nanotechnology (construction of functional structures on the nanometer scale) to the treatment, diagnosis, monitoring, and control of biological systems (Yang et al., 2015; Li et al., 2019; Wei et al., 2019). This field has seen the development of a number of drug delivery platforms, including polymer-drug conjugates ( $\mathrm{Li}$ and Wallace, 2008; KarolczakBayatti et al., 2019), liposomes (Paasonen et al., 2010; Shen and Ye, 2019), micelles (Dehghan Kelishady et al., 2014; Alliot et al., 2019), nanoshells (Huschka et al., 2012; Russo et al., 2019), and dendrimers (Modi et al., 2014; Zhao et al., 2017). The overarching aim of nanomedicine development is to design more specific drug delivery and targeting therapies as alternatives to conventional therapies.

Paclitaxel (PTX) and carboplatin (CPT) are first-line cancer chemotherapy (Barcelos et al., 2019). PTX (MW $853.9 \mathrm{~g} / \mathrm{mol}$ ) is a hydrophobic molecule that suppresses dynamic instability of microtubules and thereby inhibits mitosis (Nogales and Wang, 2006). CPT (MW $371.3 \mathrm{~g} / \mathrm{mol}$ ) is a second-generation analog of the platinum complex called carboplatin (Zhang et al., 2016). CPT reacts with genomic DNA to yield a variety of cross-linked adducts within and between DNA strands as well as between DNA and proteins, which interfere with DNA transcription (Rabik and Dolan, 2007; Thibault et al., 2018). When used together, PTX and CPT can show effective synergistic anticancer activity, yet they also frequently cause toxicity that reduces quality of life (Tourell et al., 2017). Toxicities associated with CPT involve mainly myelosuppression, principally thrombocytopenia (Nunes et al., 2018). PTX toxicity arises not only from the drug itself but also from the high concentration of the Cremophor EL vehicle, which is required to solubilize the poorly aqueous PTX into an injectable solution. The most common toxicities associated with Cremophor EL include acute hypersensitivity reactions, which are recognizable as flushing, rash, dyspnea and tachycardia (Bhatt et al., 2019; Bressand et al., 2019).

Here we developed a novel nanoscale delivery platform that allows co-delivery of PTX and CPT in a formulation that reduces the drugs' toxic effects and potentially improves efficacy. The platform comprises amphiphilic phosphonated calixarene (P4C6) assembled into a supramolecular cone. The P4C6 molecule consists of calix[4]arene with four ionizable phosphonic acid groups attached to the upper rim and four sixcarbon alkyl moieties attached to the lower rim (Figure 1). The alkylated analogs of phosphonated calix [4] arenes are amphiphilic molecules that can self-assemble via interactions between the polar head groups and hydrophobic interactions between the alkyl chains (Mo et al., 2015, 2016, 2017; Chen et al., 2017). In this way, P4C6 molecules self-assemble into a liposomal structure, with the hydrophilic $\mathrm{PO}_{3}^{-3}$ groups extending into the aqueous environment and the internal hydrophobic alkyl chains forming the layers of liposome. Through a combination of liposomal and host-guest drug-loading techniques, our laboratory has succeeded in loading hydrophobic PTX into the core of P4C6 nanoparticles and hydrophilic CPT into the anionic "bowl" of individual P4C6 molecules (Mo et al., 2015, 2016, 2017).

In the present study, we characterized the size of empty and drug-loaded P4C6 carriers over a range of biologically relevant $\mathrm{pH}$ values, determined the optimized ratio between PTX and CPT, and evaluated nanoparticle cytotoxicity against colon cancer cell lines. Finally, we evaluated the ability of the nanoparticles to inhibit colon cancer tumor growth in mice.

\section{MATERIALS AND METHODS}

\section{Materials}

All materials and reagents were purchased from commercial sources and used as received. CPT, dimethyl sulfoxide (DMSO), 3-[4,5-dimethylthiazol-2-yl]-2,5-diphenyltetrazolium bromide (MTT) and trypan blue were purchased from Sigma-Aldrich (St. Louis, MO, USA). Phosphate-buffered saline (PBS), fetal bovine serum (FBS), penicillin/streptomycin, trypLE express enzyme, McCoy's 5A media and Ham's F-12K (Kaighn's) nutrient mix were purchased from Life Technologies (Carlsbad, CA, USA). Paclitaxel was sourced from 21 CEC PX Pharm Ltd., (East Sussex, UK); chloroform and hydrochloric acid, from APS Chemicals (Canning Vale, WA, Australia); and sodium hydroxide, from Ajax FineChem (Scoresby, VIC, Australia). P4C6 was synthesized in our lab to a purity of $>95 \%$, as confirmed by HPLC (Mo et al., 2015).

\section{Cell Culture}

The two human colon cancer cell lines Caco-2, which show features of colonic epithelial cells, and HT-29, which resemble colonic crypt cells, were obtained from the American Type Culture Collection (ATCC). Caco-2 cells were grown in McCoy's $5 \mathrm{~A}$ medium supplemented with FBS $(10 \% \mathrm{v} / \mathrm{v})$ and penicillinstreptomycin $(1 \% \mathrm{v} / \mathrm{v})$. HT-29 cells were grown in Ham's F$12 \mathrm{~K}$ (Kaighn's) medium supplemented with FBS (10\% v/v) and penicillin-streptomycin (1\% v/v). When cells reached $80-100 \%$ confluence, they were trypsinized with trypLE express enzyme, centrifuged at $300 \mathrm{~g}$ for $3 \mathrm{~min}$ in a $2-16 \mathrm{PK}$ refrigerated centrifuge (Sigma Laborzentrifugen, Osterode am Harz, Germany), and split 1:4 in fresh medium.

\section{Synthesis of Compound P4C6}

P4C6 was synthesized as described previously (Mo et al., 2015). Briefly, n-hexyl groups were attached to the lower rim of calix[4]arene reaction with bromohexane and sodium hydride in DMF, the so-called Duff reaction enabled formylation, and the formylated compound was reduced to alcohol on the upper rime of calix[4]arene by sodium borohydride. The alcoholic group was chlorinated by thionyl chloride, phosphorylated by triethylphosphite and finally deprotected by 

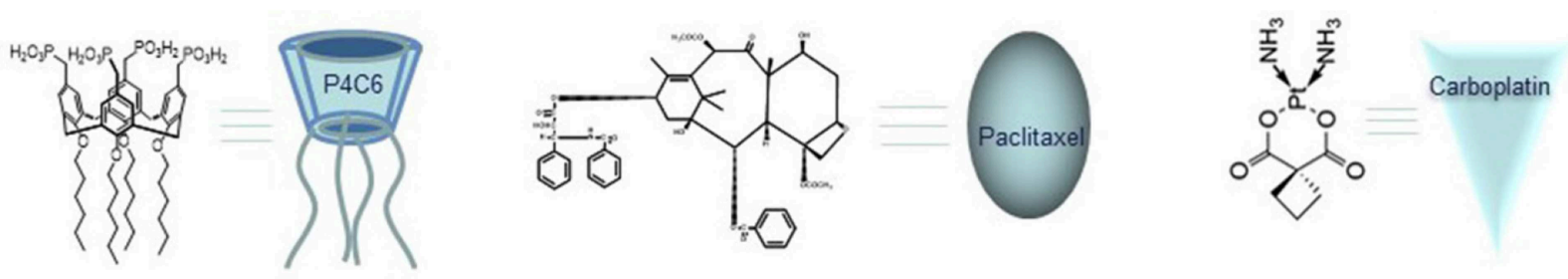

Schematic diagram for co-loading:

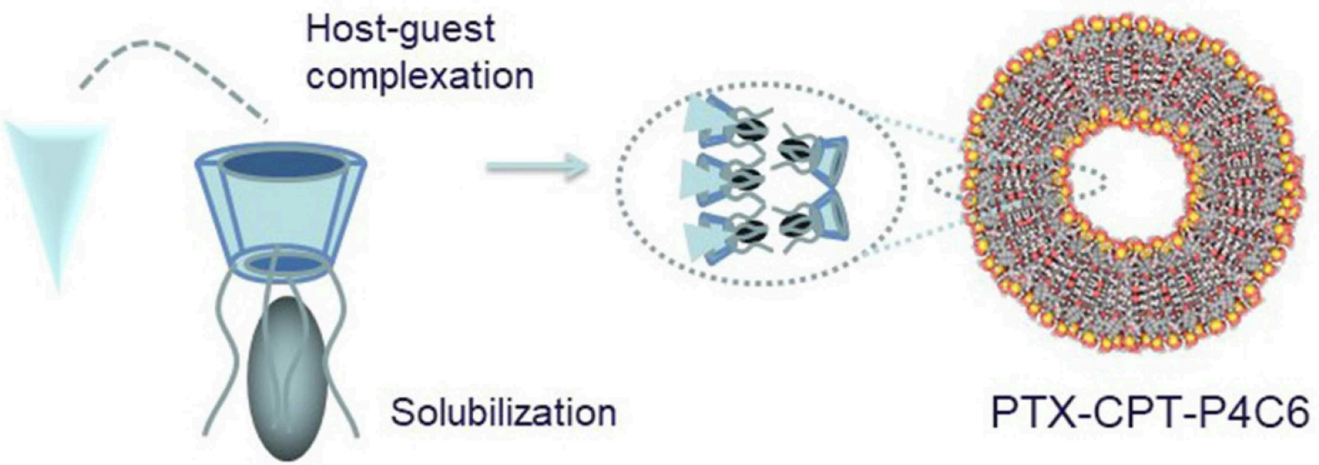

FIGURE 1 | Calixarene cone formation creates a bowl-shaped cavity for CPT and an internal core for PTX, giving rise to a dual-loaded nanoparticle (PTX-CPT-P4C6).

bromotrimethylsilane. The chemical structure of the resultant P4C6 was confirmed by ${ }^{1} \mathrm{H}$ NMR (Mercury 400, Varian, Palo Alto, CA; Figure S1).

\section{Preparation of PTX-CPT Mixture}

PTX and CPT were precisely weighed and dissolved, respectively, in $1 \%$ DMSO or pure water to a final concentration of $1 \mathrm{mg} / \mathrm{ml}$. These stock solutions were mixed to obtain different ratios of PTX:CPT for subsequent experiments.

\section{Preparation of PTX- and/or CPT-Loaded P4C6 Nanoparticles and Empty P4C6 Nanoparticles}

PTX- and/or CPT-loaded P4C6 nanoparticles were prepared as we described previously (Mo et al., 2017). Briefly, P4C6 (150 mg) was mixed with PTX (5 mg) in $50 \mathrm{~mL}$ of ethyl acetate in a $150-\mathrm{mL}$ round-bottom flask. The flask was left on a rotary evaporator (Buchi) overnight in a $40^{\circ} \mathrm{C}$ water bath to eliminate ethyl acetate. The resulting thin film was rehydrated at $40^{\circ} \mathrm{C}$ for $30 \mathrm{~min}$ in $30 \mathrm{~mL}$ of deionized water containing CPT (10 mg), after which the suspension was sonicated for $10 \mathrm{~min}$ using a probe sonicator (Qsonica L.L.C, Newtown, CT, USA; $500 \mathrm{~W}, 220 \mathrm{~V}$ ) at at $-20^{\circ} \mathrm{C}$ until experiments. PTX- or CPT-loaded P4C6 nanoparticles or empty P4C6 nanoparticles were prepared following the same procedure as above but leaving out PTX and/or CPT.

\section{Physicochemical Characterization of Nanoparticles}

Each batch of nanoparticles was characterized using dynamic light scattering (DLS) to determine particle size and size distribution, and by electrophoretic light scattering to measure zeta potential. Measurements were made with a $4-\mathrm{mW} \mathrm{He}-$ $\mathrm{Ne}$ laser at $633 \mathrm{~nm}$ and with a measurement angle of $173^{\circ}$ (Zetasizer Nano S, Malvern Instruments, Worcestershire, UK). For particle size calculations, we used the refractive index (1.330) and viscosity (0.887) of water at $25^{\circ} \mathrm{C}$, and we used its dielectric constant (78.5) for zeta potential measurements. Average values for nanoparticle size and zeta potential were calculated by the equipment, and the polydispersity index was also measured. The concentrations of PTX and CPT were determined using a method based on liquid chromatography and time-of-flight mass spectrometry (LC/TOF MS) as described in Supplementary Information (Mo et al., 2014). The entrapment efficiency (EE) was calculated from the following equation:

$$
E E(\%)=\frac{\text { amount of paclitaxle }(\text { or carboplatin) in nanoparticle pellet }(\mu g)}{\text { amount of paclitaxel (or carboplatin) in nanoparticle dispersion }(\mu g)} \times 100 \%
$$

$50 \%$ strength. The solution was passed through a $0.5-\mu \mathrm{m}$ filter (Millipore) to remove insoluble material, and the resulting PTX-CPT-P4C6 nanoparticles were freeze-dried and stored
The drug loading (DL) of PTX or CPT in the freezedried nanoparticles powder was calculated using the following equation: 


$$
D L(\%)=\frac{\text { amount of paclitaxel }(\text { or carboplatin }) \text { in freeze }- \text { dried nanoparticle }(\mu g)}{\text { amount of freeze }- \text { dried nanoparticle }(\mu g)} \times 100 \%
$$

The EE and DL of PTX and CPT were determined from three separately prepared nanoparticles, and were expressed as the mean \pm standard deviation.

For transmission electron microscopy, nanoparticles were diluted 1:30 (v/v) in MilliQ water. One drop of the diluted dispersion was deposited onto copper-coated carbon grids (Polysciences, Inc., Warrington, PA, USA). The grids were dried at ambient temperature for 3 days, then images were collected using a JEM2100 transmission electron microscope (JEOL, Akishim-Shi, Tokyo, Japan) at $120 \mathrm{kV}$ and an $11 \mathrm{Mpix}$ Orius digital camera (Gatan, Pleasanton, CA, USA).

\section{Assessment of Nanoparticle Stability}

Particle size and zeta potential measurements were taken at 0, 24, 48 , and $72 \mathrm{~h}$ after preparation, during incubation in media of $\mathrm{pH}$ from 2 to 10. Each dispersion was adjusted to the specified $\mathrm{pH}$ by drop-wise addition of $\mathrm{HCl}$ to acetate buffer solution ( $\mathrm{pH} 2-6)$ or $\mathrm{NaOH}$ to phosphate buffer solution ( $\mathrm{pH} 7-10)$, and the $\mathrm{pH}$ of the samples was measured using a SevenEasy $\mathrm{pH}$ meter (Mettler Toledo, Greifensee, Switzerland). Dilution stability of $0.3 \mu \mathrm{M}$ PTX-CPT-P4C6 was assessed by dilution with $0.9 \%$ saline for up to 100 times. The particle size distribution profiles, polydispersity index (PDI) and zeta potential values of the corresponding samples were immediately characterized by DLS.

\section{Nanoparticle Cytotoxicity in vitro}

Caco-2 and HT-29 cells were seeded onto 96-well plates at a concentration of 10,000 cells/well together with $200 \mu \mathrm{l}$ of McCoy's 5A medium or Ham's F-12K (Kaighn's) medium, respectively. The cells were incubated for $24 \mathrm{~h}$ at $5 \% \mathrm{CO}_{2}$ and $37^{\circ} \mathrm{C}$, before the medium in each well was replaced with an equal volume of medium containing the appropriate concentration of samples. Plates were then incubated in a humidified atmosphere containing $5 \% \mathrm{CO}_{2}$ at $37^{\circ} \mathrm{C}$ for 2 or $48 \mathrm{~h}$. For experiments involving 2 -h exposure, sample-containing medium was aspirated after $2 \mathrm{~h}$, and replaced with $200 \mu \mathrm{l}$ of fresh, drug-free culture medium. The cells were then incubated another $46 \mathrm{~h}$, and finally analyzed in the MTT assay. For experiments involving 48-h exposure, cells were processed in the MTT assay immediately after the 48-h incubation.

MTT was dissolved in PBS at a concentration of $5 \mathrm{mg} / \mathrm{ml}$. Each well of cells was incubated with $20 \mu \mathrm{l}$ of this mixture for $3 \mathrm{~h}$, excess MTT was aspirated and DMSO was added (200 $\mu \mathrm{l} /$ well), and plates were incubated for $15 \mathrm{~min}$ at ambient temperature away from light. Plates were then analyzed at $595 \mathrm{~nm}$ on a Multiskan RC Microplate Reader (Thermo/LabSystems, Champaign, IL, USA). Cell survival percentages relative to control cells exposed to medium without any nanoparticle or drugs were plotted as a function of nanoparticle or drug concentration on a logarithmic scale. A dose-response curve was generated using three-parameter, non-linear inhibition doseresponse fitting in Prism 6.05 (GraphPad Software, La Jolla, CA,
USA). The half-maximal inhibitory concentration $\left(\mathrm{IC}_{\mathbf{5 0}}\right)$ was determined based on this curve.

The chemomodulatory effect of carboplatin (CPT) to paclitaxel (PTX) within colon cancer cells was determined using combination analysis between PTX and CPT as previously described (Chen et al., 2017). Briefly, exponentially growing HT-29 and CaCo-2 cells were seeded in 96-well plates (2,000 cells/well) and exposed to fixed concentrations of PTX and CPT (molar ratio of 5.22:1) for 2 and $48 \mathrm{~h}$. Cells were subsequently subjected to MTT assay as described in the previous section. Combination index (CI-value) was calculated and used to define the nature of drug interaction (synergism if CI-value $<0.8$ as; antagonism if CI-value $>1.2$; and additive if CI-value ranges from 0.8 to 1.2 ). CI value was calculated from the formula:

$$
\begin{aligned}
\text { CI value } & =\frac{\mathrm{IC}_{50} \text { of drug }(\mathrm{PTX}) \text { combination }}{\mathrm{IC}_{50} \text { of drug }(\mathrm{PTX}) \text { alone }} \\
& +\frac{\mathrm{IC}_{50} \text { of drug }(\mathrm{CPT}) \text { combination }}{\mathrm{IC}_{50} \text { of drug }(\mathrm{CPT}) \text { alone }}
\end{aligned}
$$

\section{Effects of Nanoparticles on Apoptosis and Cell Cycle Distribution in vitro}

Caco-2 and HT-29 cells were seeded in 6-well plates with $2 \mathrm{ml}$ of McCoy's 5A medium or Ham's F-12K (Kaighn's) medium, respectively. After allowing cells to adhere for $24 \mathrm{~h}$, the medium was replaced with $2 \mathrm{ml} \mathrm{P4C6}(200 \mu \mathrm{M})$, PTX-CPT mixture (5 $\mu \mathrm{M}$ PTX and $26.1 \mu \mathrm{M}$ CPT) or PTX-CPT-P4C6 (0.3 $\mu \mathrm{M}$ PTX and $1.57 \mu \mathrm{M}$ CPT). Negative controls are Caco-2 and HT-29 cells cultured as the same procedure as above without any treatment. The plates were incubated in a humidified atmosphere containing $5 \% \mathrm{CO}_{2}$ at $37^{\circ} \mathrm{C}$ for $48 \mathrm{~h}$ (Forma ${ }^{\mathrm{TM}}$ Series II Water-Jacketed $\mathrm{CO}_{2}$ Incubator, Thermo Fisher Scientific, Waltham, MA, USA).

The cells were then prepared for flow cytometry using a FITCAnnexin V/Dead Cell Apoptosis Kit (Sigma-Aldrich) according to the manufacturer's protocol. Briefly, harvested cells from each well were washed with $1 \mathrm{ml}$ of PBS, centrifuged ( $300 \mathrm{~g}$ for $3 \mathrm{~min}$ ) and the pellet was resuspended in $100 \mu \mathrm{l} 1 \mathrm{X}$ annexin-binding buffer, together with $5 \mu \mathrm{l}$ of FITC and $1 \mu \mathrm{l}$ of propidium iodide (PI; $100 \mu \mathrm{g} / \mathrm{ml}$ ). The sample was incubated for $15 \mathrm{~min}$ at ambient temperature, then an additional $400 \mu \mathrm{l}$ of $1 \mathrm{X}$ annexin-binding buffer was added. For cell cycle distribution analysis, the treated and untreated cells were washed and re-suspended in $1 \mathrm{~mL}$ of PBS containing $50 \mu \mathrm{g} / \mathrm{mL}$ RNAase A (Sigma-Aldrich) and $10 \mu \mathrm{g} / \mathrm{mL}$ propidium iodide (PI) (Sigma-Aldrich) for $20 \mathrm{~min}$. The samples were kept on ice until analysis. Flow cytometry was performed on a FACS Calibur Flow Cytometer (Becton Dickinson, Franklin Lake, NJ, USA) and the data were analyzed using CellQuest Pro (Becton Dickinson) to determine levels of apoptosis and distribution in the cell cycle.

\section{Cell Migration and Invasion in vitro}

In vitro cell invasion assays (also known as the Boyden transwell chamber assay) were conducted using 24-well cell culture plates 
with polycarbonate inserts (Millipore) with pore diameters of $8 \mu \mathrm{m}$. In brief, cells $\left(5 \times 10^{4}\right)$ in $300 \mu \mathrm{L}$ serum-free DMEM were seeded onto the upper chambers for $24 \mathrm{~h}$ for cells attached, then $800 \mu \mathrm{L}$ DMEM with $10 \%$ serum was added to the lower chambers. After incubation for another $24 \mathrm{~h}$ with $300 \mu \mathrm{L}$ serumfree DMEM containing P4C6 $(1.73 \mu \mathrm{g})$, PTX-CPT mixture $(0.077 \mu \mathrm{g}$ of PTX, $0.174 \mu \mathrm{g})$ or PTX-CPT-P4C6 (0.077 $\mu \mathrm{g}$ of PTX, $0.174 \mu \mathrm{g}$ of CPT, and $1.73 \mu \mathrm{g}$ of P4C6), the supernatant containing treatments was aspirated. Fresh medium was then added and cells were incubated a further $48 \mathrm{~h}$. Cells that had not penetrated the filter were wiped away with cotton swabs, and cells that had migrated to the lower surface of the filter were counted in five randomly selected fields at $40 \times$ magnification using a light microscope (Olympus, Japan). Each assay was performed in triplicate.

Effects of different formulations on HT-29 cell migratory activity were examined in a wound healing assay. Cells were cultured in six-well plates in a $5 \% \mathrm{CO}_{2}$ incubator for $24 \mathrm{~h}$ until completely confluent. The cell monolayer was scratched with a $200-\mu \mathrm{L}$ pipette tip to inflict a wound, cells were washed twice in PBS to remove floaters, and the medium was replaced by $2 \mathrm{~mL} 0.5 \%$ FBS DMEM containing P4C6 (11.54 mg) or PTXCPT mixture (0.51 mg PTX, $1.16 \mathrm{mg}$ CPT) or PTX-CPT-P4C6 (0.51 mg of PTX, $1.16 \mathrm{mg}$ of CPT and $11.54 \mathrm{mg}$ of P4C6). After another $24 \mathrm{~h}$ of incubation, the supernatant was aspirated and replaced with fresh medium without any nanoparticles or drugs, and the cultures were incubated another $96 \mathrm{~h}$. Migration of cells from the leading edge was analyzed using light microscopy. Relative gap area was measured using imageJ software (NIH, USA), and the ratio of gap area for each group at $96 \mathrm{~h}$ relative to the gap area in each group at $0 \mathrm{~h}$ was plotted.

\section{Anti-tumor Effects of Nanoparticles in vivo}

Female Balb/c nude mice aged 5-6 weeks were obtained from the Model Animal Research Center of Nanjing University (Nanjing, China). All animal experiments were approved by the Ethics Committee of Guilin Medical University (ethics number YXLL2016-088). HT-29 cells $\left(2 \times 10^{6}\right.$ in $100 \mu \mathrm{L}$ PBS $)$ were injected subcutaneously into the upper right thigh of mice. Treatments with different formulations were initiated when tumors had reached a volume of $200 \mathrm{~mm}^{3}$. Mice were randomly divided into four groups (5 per group): the empty P4C6 nanoparticles group, $8.73 \mathrm{mg} / \mathrm{kg}$ P4C6; the PTX-CPT group, $1.27 \mathrm{mg} / \mathrm{kg}$ PTX-CPT $(0.39 \mathrm{mg}+0.88 \mathrm{mg})$; the PTX-CPT-P4C6 group, $10 \mathrm{mg} / \mathrm{kg}$ PTXCPT-P4C6 (containing $0.39 \mathrm{mg}$ PTX, $0.88 \mathrm{mg} \mathrm{CPT}$, and $8.73 \mathrm{mg}$ $\mathrm{P} 4 \mathrm{C6}$ ) and control group, $0.9 \%$ saline. These treatments were administered by oral gavage once every other day after body weight and tumor volume had been recorded. Tumor volume was calculated according to the following equation.

$$
\text { Tumor volume } \begin{aligned}
\left(\mathrm{mm}^{3}\right) & =0.5 \times \text { long axis }(\mathrm{mm}) \\
& \times[\text { short axis }(\mathrm{mm})]^{2}
\end{aligned}
$$

Tumors were not allowed to grow beyond $3,000 \mathrm{~mm}^{3}$, in accordance with our institutional animal care guidelines. Once the maximum tumor volume was reached, the animal was euthanized with pentobarbital.
The mice were euthanized on day 12 of drug administration. Tumor tissues were removed completely and weighed. Tumors, livers, and kidneys were fixed in formalin, embedded in paraffin, thin-sliced, and stained with hematoxylin-eosin for histological analysis. Blood was collected from the postcaval vein, centrifuged at $1,006 \mathrm{~g}$ for $10 \mathrm{~min}$, and the serum supernatant was assayed for aspartate aminotransferase and blood urea nitrogen levels using a blood autoanalyzer (CDC Technologies, OH, USA).

For staining with Annexin V and PI, the tumors were cut into slices $5.0 \mu \mathrm{m}$ thick, placed on slides, washed with PBS three times, then incubated with binding buffer containing Annexin $\mathrm{V}$ and PI for $15 \mathrm{~min}$ at $25^{\circ} \mathrm{C}$ in the dark. Finally, samples were washed, stained for nuclei using DAPI ( $5 \mathrm{mM})$, and examined by confocal microscopy (Leica TCS SP5, Germany).

To further determine the degree of apoptosis-like cell death, terminal deoxynucleotidyl transferase-mediated dUTP endlabeling (TUNEL) (Nanjing Jiancheng Bioengineering Institute, Nanjing, China) was performed. Tumor sections of different treatment groups were processed according to the manufacturer's protocol, and examined using a light microscope (ECLIPSE 80i, Nikon, Tokyo, Japan).

\section{Statistical Analyses}

Data were presented as mean $\pm \mathrm{SD}$. Variance analysis and $t$-tests were used to assess the significance of differences. Differences were considered significant at three levels: ${ }^{*} p<0.05$, ${ }^{* *} p<$ 0.01 , and ${ }^{* * *} p<0.001$. All batches were produced in triplicates otherwise mentioned. Each experiment was repeated twice.

\section{RESULTS}

\section{Physicochemical Characterization of Nanoparticles}

In the dual-loaded formulation of PTX-CPT-P4C6, EE and DL were $87.66 \pm 6.07$ and $3.88 \pm 0.86 \%$ for PTX, and $56.6 \pm 3.88$ and $8.79 \pm 0.28 \%$ for CPT. In the single-loaded formulations of PTXP4C6 and CPT-P4C6, rather higher EE and DL were observed as $91.28 \pm 11.07$ and $4.93 \pm 0.51 \%$ for PTX, and $58.85 \pm 5.06$ and $11.5 \pm 2.8 \%$ for CPT (Table 1 ).

Average hydrodynamic diameter and polydispersity index were $84 \pm 8 \mathrm{~nm}$ and $0.22 \pm 0.01$ for empty P4C6 nanoparticles, compared to $119 \pm 13 \mathrm{~nm}$ and $0.21 \pm 0.01$ for PTX-CPT-P4C6

TABLE 1 | Characterization of various nanoparticle formulations by DLS and

\begin{tabular}{|c|c|c|c|c|}
\hline Formulations & $\begin{array}{l}\text { Particle size } \\
(\mathrm{nm})\end{array}$ & PDI & $\begin{array}{l}\text { Zeta } \\
\text { potential } \\
(\mathrm{mV})\end{array}$ & $\begin{array}{l}\text { Loading } \\
\text { efficiency } \\
(\%)\end{array}$ \\
\hline $\begin{array}{l}\text { Empty P4C6 } \\
\text { nanoparticles }\end{array}$ & $84 \pm 8$ & $0.22 \pm 0.01$ & $-40.8 \pm 8.8$ & N/A \\
\hline $\begin{array}{l}\text { PTX-CPT- } \\
\text { P4C6 }\end{array}$ & $119 \pm 13$ & $0.21 \pm 0.01$ & $-35.4 \pm 4.2$ & $\begin{array}{c}3.88 \pm 0.86 \\
(\mathrm{PTX}) \\
8.79 \pm 0.28 \\
(\mathrm{CPT})\end{array}$ \\
\hline PTX-P4C6 & $121 \pm 13$ & $0.26 \pm 0.05$ & $-39.8 \pm 9.2$ & $4.93 \pm 0.51$ \\
\hline СРT-P4C6 & $130 \pm 18$ & $0.22 \pm 0.07$ & $-36.6 \pm 6.8$ & $11.5 \pm 2.8$ \\
\hline
\end{tabular}
LC/TOF MS. 

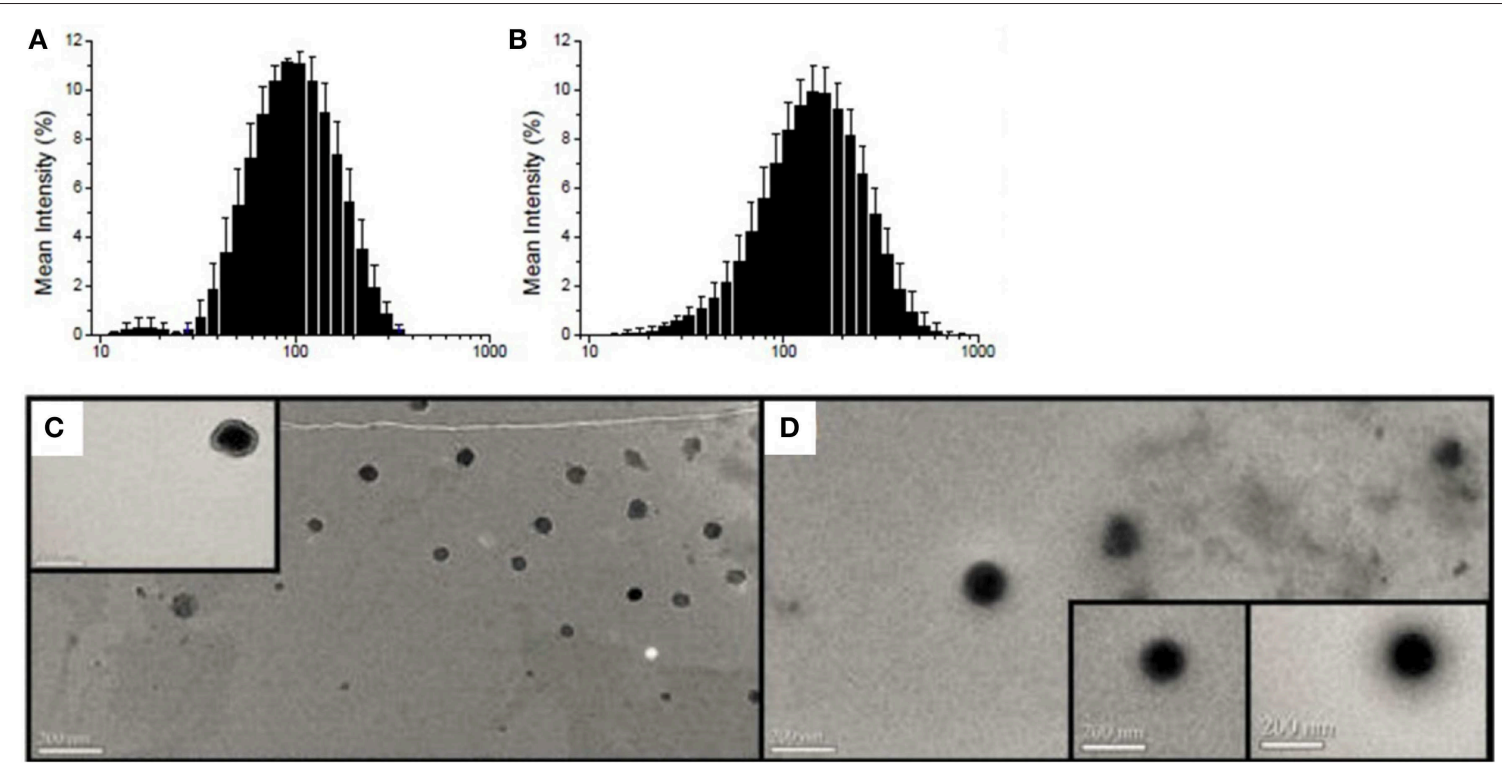

FIGURE 2 | Particle size distribution ( $\mathrm{nm}$ ) as determined by dynamic light scattering: (A) empty P4C6 nanoparticles and (B) PTX-CPT-P4C6; Transmission electron micrographs of (C) empty P4C6 nanoparticles and (D) PTX-CPT-P4C6. Scale bar, $200 \mathrm{~nm}$.

(Figure 2). Loading P4C6 with both PTX and CPT significantly increased mean particle size $(p \leq 0.01)$. Zeta potential was not significantly different between empty P4C6 nanoparticles $(-40.8$ $\pm 8.8 \mathrm{mV})$ and PTX-CPT-P4C6 $(-35.4 \pm 4.2 \mathrm{mV})$. Compared to dual-loaded P4C6 nanoparticles, loading P4C6 with either PTX or CPT would slightly increase the corresponding nanoparticle sizes and loading efficiencies as well. In all nanoparticle formulations, their PDI and zeta potentials were of no comparative differences (Table 1).

Transmission electron microscopy showed empty P4C6 nanoparticles and PTX-CPT-P4C6 nanoparticles to be uniformly round (Figures 2C,D) and to have diameters consistent with those determined by dynamic light scattering.

\section{Nanoparticle Stability}

Figure 3 shows average size of empty P4C6 nanoparticles and PTX-CPT-P4C6 nanoparticles during 72-h storage at ambient temperature in the dark. Neither mean particle size nor zeta potential of PTX-CPT-P4C6 changed significantly during storage (Figure 3). In contrast, empty P4C6 nanoparticles did not change significantly in size, but their zeta potential decreased significantly between 24 and $72 \mathrm{~h}(p \leq 0.05)$.

It can be observed from Figure S2 that there were no significant changes in the mean particle size of PTX-CPT-P4C6 upon dilution with $0.9 \%$ saline (up to 100 times, $p>0.05$ ). At the same time, the polydispersity index and zeta potential slightly increased with multiple times dilution, though the difference is negligible.

To assess nanoparticle stability across a pharmaceutically relevant $\mathrm{pH}$ range, the $\mathrm{pH}$ of empty $\mathrm{P} 4 \mathrm{C6}$ nanoparticles and PTX-CPT-P4C6 dispersions was gradually adjusted to specific values $(\mathrm{pH} 2-10)$. In no case did mean particle size or size distribution vary substantially at $\mathrm{pH}$ values up to 10 (Figure 4A). Similarly, zeta potential did not vary significantly over this $\mathrm{pH}$ range (Figure 4B).

\section{Nanoparticle Cytotoxicity in vitro}

Empty P4C6 nanoparticles showed an $\mathrm{IC}_{50}$ of $2050.8 \pm 2.2 \mu \mathrm{M}$ against HT-29 cells and $1340.9 \pm 1.5 \mu \mathrm{M}$ against Caco-2 cells (Figure 5).

Next, we determined the $\mathrm{IC}_{50}$ of combinations of CPT and PTX mixed in three molar ratios, 5.22:0.5, 5.22:1, and 5.22:2. Our goal was to optimize the ratio of the two drugs in the dual-drug delivery platform PTX-CPT-P4C6. Of the three ratios tested, the ratio 5.22:1 was the most cytotoxic to HT-29 and Caco-2 cells (Figure S3, Table 2), so this ratio was used in all subsequent experiments.

The therapeutic efficacy of this molar ratio was confirmed in two ways. First, PTX-CPT-P4C6 formulated with this ratio showed significantly lower $\mathrm{IC}_{\mathbf{5 0}}$ at $24 \mathrm{~h}$ than the simple PTXCPT mixture prepared with that ratio (Table 3). Second, doseresponse curves showed significantly lower $\mathrm{IC}_{50}$ for PTX-CPTP4C6 than for PTX-CPT mixture at 2 and $48 \mathrm{~h}$ (Figure S4, Table 3).

Under $48 \mathrm{~h}$ incubation period, cytotoxicity of CPT was weaker in CaCo-2 cells compared to HT-29 cells with $\mathrm{IC}_{50}$ s of $16.2 \pm 2.9$ and $13.1 \pm 2.1 \mu \mathrm{M}$, respectively. However, CPT synergistically improved the cytotoxic profile of PTX against both colon cancer cell lines. Under $48 \mathrm{~h}$ incubation period, CPT significantly decreased the $\mathrm{IC}_{50} \mathrm{~s}$ of PTX from $13.9 \pm 2.1$ and $20.8 \pm 3.8 \mu \mathrm{M}$ to $0.4 \pm 0.02$ and $2.1 \pm 0.3 \mu \mathrm{M}$ in HT-29 and CaCo-2 cells, respectively. The combination indices for PTX and CPT (molar ratio of 5.22:1) within HT-29 and CaCo-2 cells were 0.15 and 0.37 , respectively (Table 3 ). 

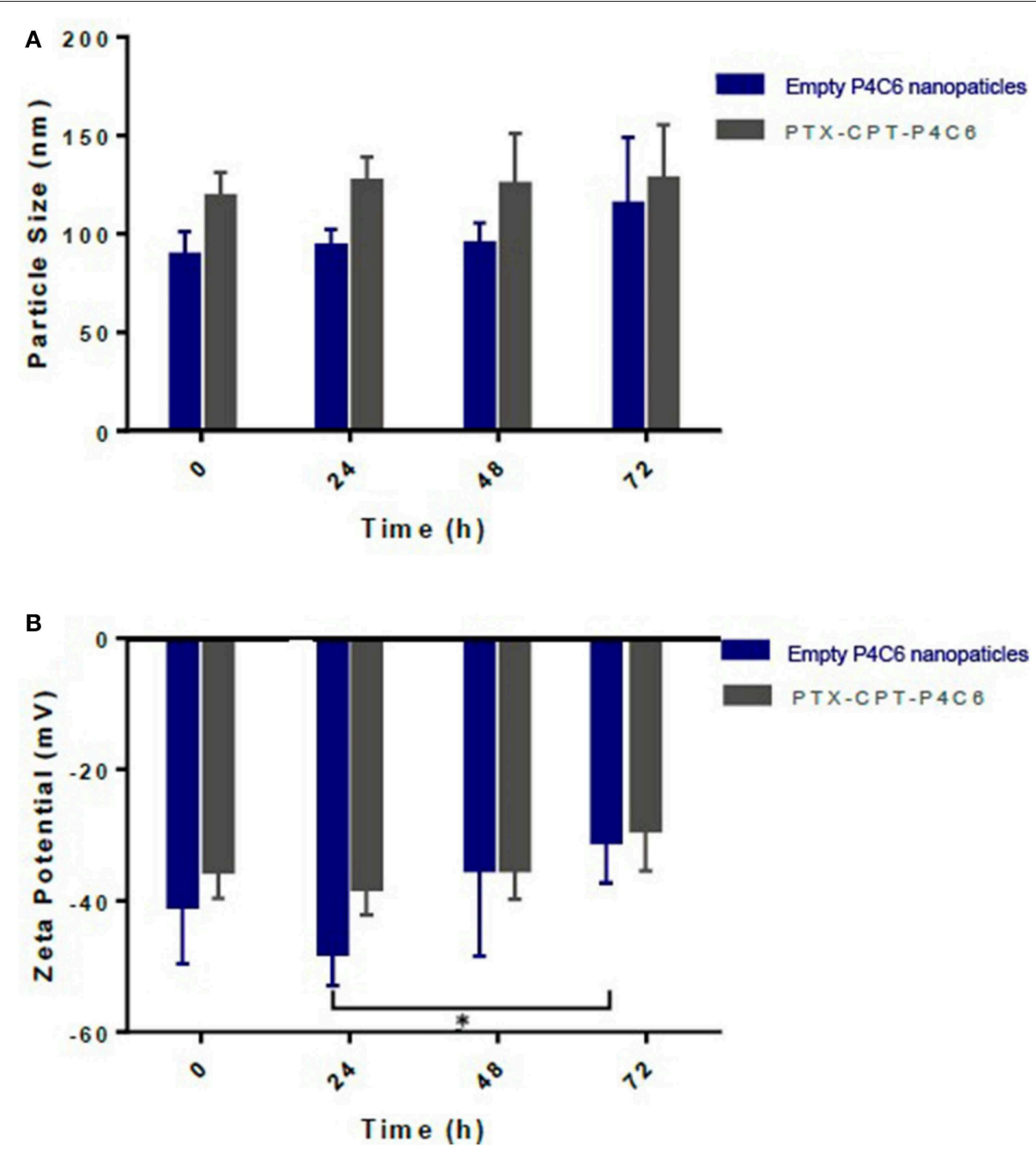

FIGURE 3 | Changes in different nanoparticles during 72-h storage in terms of (A) size as measured using dynamic light scattering and (B) zeta potential as measured using electrophoretic light scattering.

\section{Effects of Nanoparticles on Apoptosis and Cell Cycle Distribution in vitro}

The induction of apoptosis by PTX-CPT-P4C6 was confirmed in flow cytometryic analysis (Figures 6A,C), where proportions of apoptotic Caco-2 and HT-29 cells were much higher after treatment with $0.3 \mu \mathrm{M}$ PTX-CPT-P4C6 nanoparticles (44.9 \pm 3.44 and $56.6 \pm 4.5 \%)$ than after treatment with $0.3 \mu \mathrm{M}$ PTXCPT $(10.4 \pm 1.05$ and $15.1 \pm 1.9 \%)$. In other words, loading the two drugs into P4C6 nanoparticles increased their pro-apoptotic efficacy about 4-fold in Caco-2 cells and HT-29 cells.

Treating Caco-2 cells with $0.3 \mu \mathrm{M}$ PTX-CPT-P4C6 for $48 \mathrm{~h}$ led to arrest of $48.2 \pm 6.24 \%$ of cells in the G2/M-phase, compared to $30.4 \pm 3.27$ or $34.1 \pm 2.79 \%$ of cells after treatment with empty P4C6 nanoparticles or the same concentration of PTX-CPT $(p<0.05$; Figure 6B). Similarly, treating HT-29 cells with $0.3 \mu \mathrm{M}$ PTX-CPT-P4C6 led to arrest of $50.4 \pm 5.51 \%$ of cells in G2/M-phase, compared to $33.9 \pm 4.08$ or $36.7 \pm 3.53 \%$ with free P4C6 nanoparticles or PTX-CPT ( $p<0.05$; Figure 6D).
These two sets of experiments suggest that apoptosis induction and mitotic arrest help explain the observed ability of micelle-encapsulated PTX and CPT to inhibit tumor cell proliferation.

\section{Effects of Nanoparticles on Invasion and Migration of HT-29 Cells in vitro}

To observe the effects of different formulations on the invasion of HT-29 cells in a three-dimensional setting, the Boyden transwell chamber assay was performed. The number of invasive cells in the PTX-CPT-P4C6 group (64 \pm 14 cells per field of view) was significantly lower than that in the PTX-CPT group (219 \pm 34 ; Figures 7A,B). Similarly, in the wound healing assay, the wounded area in the PTX-CPT-P4C6 group was $83.9 \pm 7.2 \%$ of the original area after $96 \mathrm{~h}$, compared to $57.1 \pm 5.4 \%$ in the PTXCPT group and $35.7 \pm 4.2 \%$ in the empty P4C6 nanoparticles group (Figures 7C,D). 

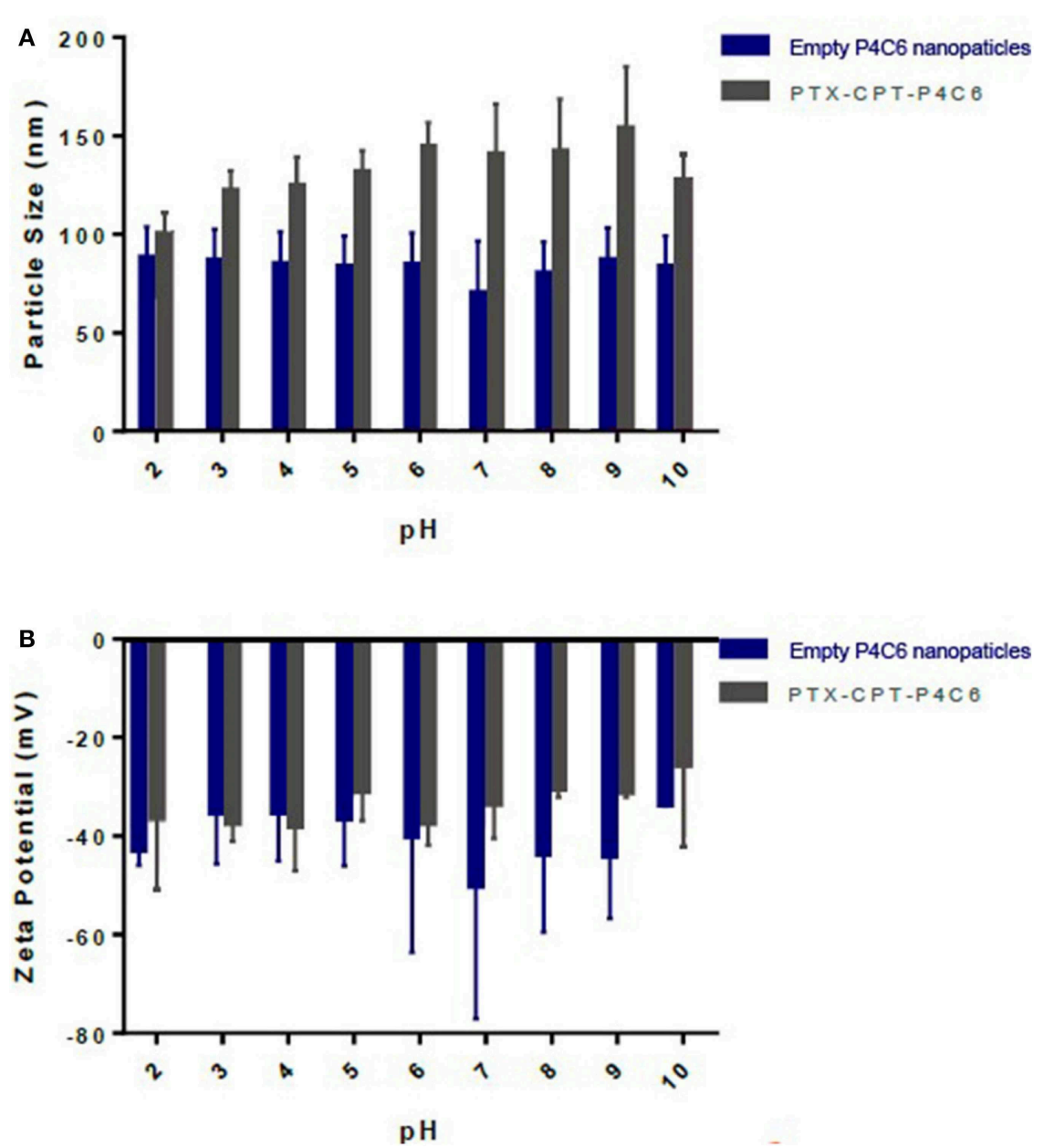

FIGURE 4 | Effects of pH on different nanoparticles (A) size and (B) zeta potential.
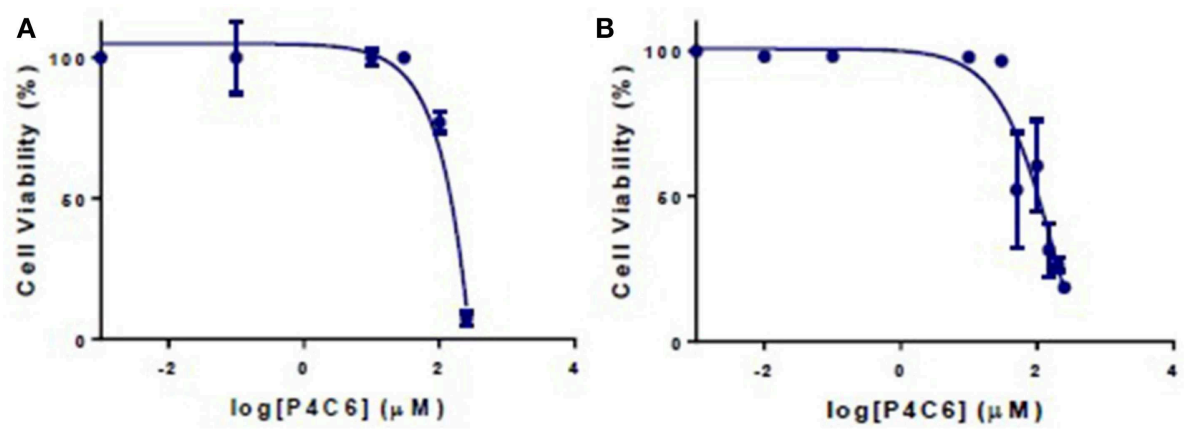

FIGURE 5 | Viability of (A) Caco-2 and (B) HT-29 cells after $24 \mathrm{~h}$ treatment with different concentrations of empty P4C6 nanoparticles. Viability was measured in the MTT assay.

\section{Effect of Nanoparticles on HT-29 Human Colon Cancer Xenografts in vivo}

The in vivo antitumor efficacy of the PTX-CPT-P4C6 was investigated on HT-29 human breast tumor-bearing nude mice. Animals were treated by oral gavage with PBS or different drug formulations every 2 days, when tumor volume were measured
(Figures 8A,B). Tumor growth was significantly suppressed by PTX-CPT and PTX-CPT-P4C6, compared to $0.9 \%$ saline and empty P4C6 nanoparticles (Figures 8B,C). Hematoxylineosin staining of tumor tissue revealed more extensive tumor cell necrosis and larger numbers of shrunken and fragmented nuclei in PTX-CPT-P4C6 tumors than in other tumors 
(Figure 8D). PTX-CPT-P4C6 nanoparticles caused the greatest tumor inhibition, and tumors from these animals showed the greatest levels of early apoptosis (based on annexin V staining) and late apoptosis (based on PI staining; Figure 8E). Coincided with annexin V-PI assay, results of TUNEL staining confirmed PTX-CPT-P4C6 could cause highest level of apoptosis of HT-29 colon cancer cells among all treatment groups (Figure 8F).

\section{Preliminary Evaluation of Nanoparticle Toxicity}

Mice were treated by oral gavage with PBS or different drug formulations every 2 days, when body weight was also measured (Figure 9A). No deaths or significant loss of body weight relative to healthy controls occurred with empty P4C6 nanoparticles, PTX-CPT, or PTX-CPT-P4C6. Aspartate aminotransferase and blood urea nitrogen levels after all treatments were similar to those in controls (Figures 9B,C), as was morphology of kidney and liver tissue based on hematoxylin-eosin staining (Figure 9D). No significant glomerular damage was observed in kidney sections, and broken hepatic cords were not seen in liver tissue. Negligible leukocyte migration to kidney or liver was observed.

\section{DISCUSSION}

Functional modification of calixarenes at the upper and/or lower rims makes it possible to derive a variety of molecules with

TABLE 2 | IC 50 values of the PTX-CPT mixture prepared in different drug ratios.

\begin{tabular}{lll}
\hline Molar ratio CPT:PTX & Against Caco-2 cells & Against HT-29 cells \\
\cline { 2 - 3 } & $\mathbf{I C}_{\mathbf{5 0}}(\boldsymbol{\mu} \mathbf{M})$ & $\mathbf{I C}_{\mathbf{5 0}}(\boldsymbol{\mu} \mathbf{M})$ \\
\hline $5.22: 0.5$ & $8.5 \pm 0.8$ & $15.9 \pm 1.5$ \\
$5.22: 1$ & $7.2 \pm 1.4$ & $2.1 \pm 0.4$ \\
$5.22: 2$ & $8.2 \pm 3.1$ & $3.0 \pm 1.3$ \\
\hline
\end{tabular}

Values are mean $\pm S D$ in terms of PTX concentration. tunable physicochemical properties and selectivity for guest molecules (Arena et al., 2000). They are also attractive for drug delivery because they can increase the poor solubility of many anticancer drugs, prolong the circulation of drugs by protecting them from premature interaction with host molecules, and improve drug penetration into the target tissue (Ngandeu Neubi et al., 2018). The present study focused on a phosphonated calix[4]arene (P4C6) capable of co-loading two commonly used anticancer agents, CPT and PTX: the CPT occupies an external bowl-shaped cavity, while PTX is solubilized between the bilayers of liposome.

The size, size distribution and zeta potential of nanoparticles are critical determinants of their toxicity (Shah and Dobrovolskaia, 2018) and bio-distribution (Graham et al., 2017). The average hydrodynamic diameters of all nanoparticles in this study can avoid renal excretion and evade detection by the mononuclear phagocytic system (Devarajan et al., 2010). All formulations showed low polydispersity, suggesting monodisperse populations and narrow size distribution. Nanoparticles remained stable for at least $72 \mathrm{~h}$ over a broad range of $\mathrm{pH}$ values and multiple times dilution. These results suggest that these drug-loaded nanoparticles can remain intact until reaching the colon.

We formulated PTX-CPT-P4C6 nanoparticles with a CPT:PTX mass ratio of 8.79:3.88\% per $1 \mathrm{~g}$ of nanoparticle, which corresponds to a molar ratio of 5.22:1. Screening a few ratios of CPT:PTX showed 5.22:1 to be most effective in cytotoxicity assays in vitro. We performed these assays using Caco-2 cells, which are heterogeneous human epithelial colorectal adenocarcinoma cells (Schreck and Melzig, 2018) used most often as a confluent monolayer rather than individual cells (Ellens et al., 2018); the monolayer can, under certain conditions, form a polarized epithelial cell monolayer (Gibaud and Attivi, 2012). Therefore Caco-2 was used here to mimic normal colorectal epithelial cells (Beloqui et al., 2016). The most common form of colon cancer is adenocarcinoma (Beloqui et al., 2016; Yueh et al., 2016), so we selected HT-29 adenocarcinoma cells as a colon cancer model. These cells are frequently used in tumorigenicity studies

TABLE 3 | IC 50 values $(\mu \mathrm{M})$ for empty P4C6 nanoparticles, PTX- and/or CPT-P4C6 nanoparticles and the simple PTX and/or CPT mixture when the two drugs were mixed in the molar ratio CPT:PTX $=5.22: 1$.

\begin{tabular}{|c|c|c|c|c|}
\hline \multirow{2}{*}{ Treatments } & \multicolumn{2}{|c|}{ Caco-2 } & \multicolumn{2}{|c|}{ HT-29 } \\
\hline & $\mathrm{IC}_{50}(\mu \mathrm{M})$ & $\mathrm{IC}_{50}(\mu \mathrm{M})$ & $\mathrm{IC}_{50}(\mu \mathrm{M})$ & $I C_{50}(\mu \mathrm{M})$ \\
\hline $\begin{array}{l}\text { Empty P4C6 } \\
\text { nanoparticles }\end{array}$ & $1204.0 \pm 94.6$ & $635.1 \pm 58.4$ & $806.9 \pm 61.5$ & $187.8 \pm 14.2$ \\
\hline CPT & $213.5 \pm 18.6$ & $16.2 \pm 2.9$ & $140.1 \pm 15.9$ & $13.1 \pm 2.1$ \\
\hline СРT-P4C6 & $110.2 \pm 14.6$ & $12.7 \pm 1.6$ & $87.6 \pm 6.2$ & $10.9 \pm 0.8$ \\
\hline PTX-CPT & $110.2 \pm 21.5$ & $6.2 \pm 0.5$ & $62.8 \pm 8.4$ & $1.7 \pm 0.3$ \\
\hline PTX-СРT-P4C6 & $25.2 \pm 3.7$ & $2.1 \pm 0.3$ & $4.6 \pm 0.3$ & $0.4 \pm 0.02$ \\
\hline Cl-index (Cl-value) & Synergism (0.44) & Synergism (0.37) & Synergism (0.62) & Synergism (0.15) \\
\hline
\end{tabular}

Data are mean $\pm S D$ 


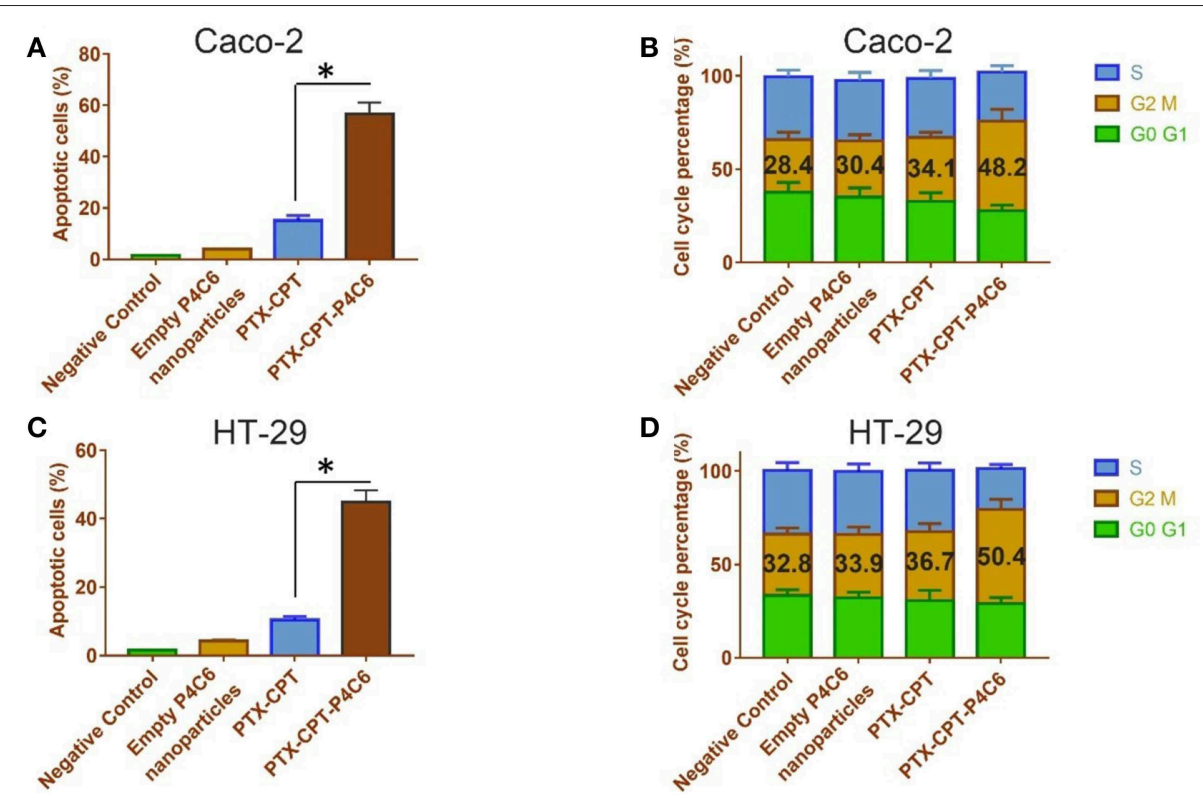

FIGURE 6 | Effects of empty P4C6 nanoparticles, PTX-CPT and PTX-CPT-P4C6 on (A,C) apoptosis and (B,D) cell cycle distribution in Caco-2 and HT-29 cultures. Negative control cultures were left untreated. ${ }^{\star} p<0.05$ (Student's t-test).

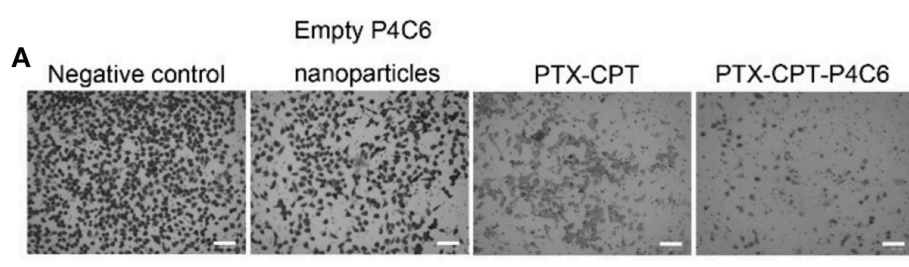

Empty P4C6

Negative control nanoparticles

C
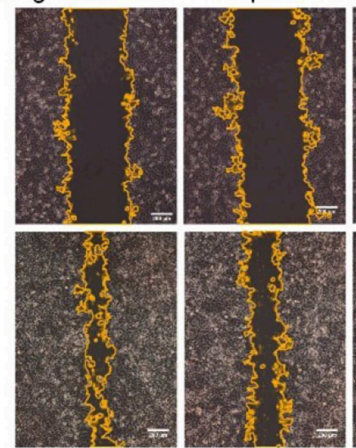

PTX-CP
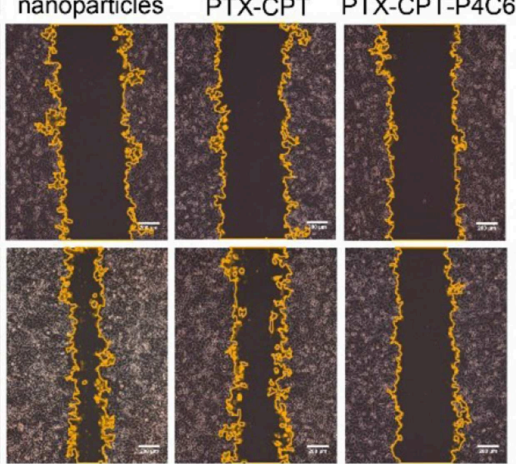

B

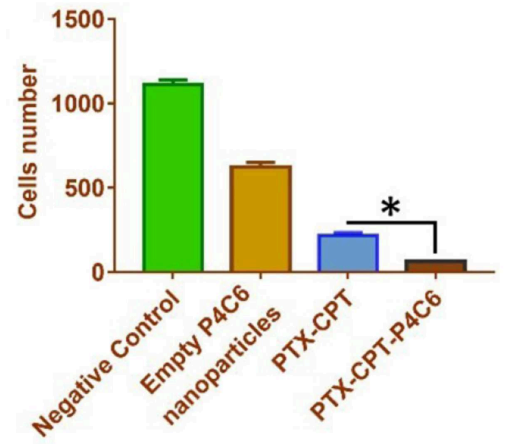

D

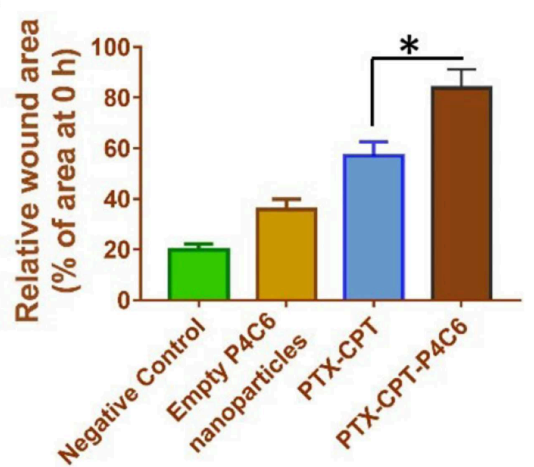

FIGURE 7 | Effects of empty P4C6 nanoparticles, PTX-CPT and PTX-CPT-P4C6 on invasion and migration of HT-29 cells. (A) HT-29 cells were treated with different formulations in serum-free medium for $24 \mathrm{~h}$ in Boyden transwell chambers. Cells that reached the bottom of membranes were counted. Negative control cultures were left untreated. Scale bar, $100 \mu \mathrm{m}$. (B) Quantitation of the transwell assay. Each bar represents the mean \pm SD of three independent observations. (C) Cells were scratched with a pipette tip, washed twice in PBS and photographed at O h, then treated with empty P4C6 nanoparticles, the mixture PTX-CPT, or PTX-CPT-P4C6. Negative control cells were left untreated. The experiment was allowed to proceed until the gap was nearly covered by migrated cells in negative control cultures (96 h). At the end of the experiment, migration was photographed under a phase-contrast microscope, and the gap area was measured using Image J software. Scale bar, $200 \mu \mathrm{m}$. (D) Quantitation of the wound healing assay. Each bar represents the mean \pm SD of three independent measurements. ${ }^{*} p<0.05$ (Student's $t$-test). 


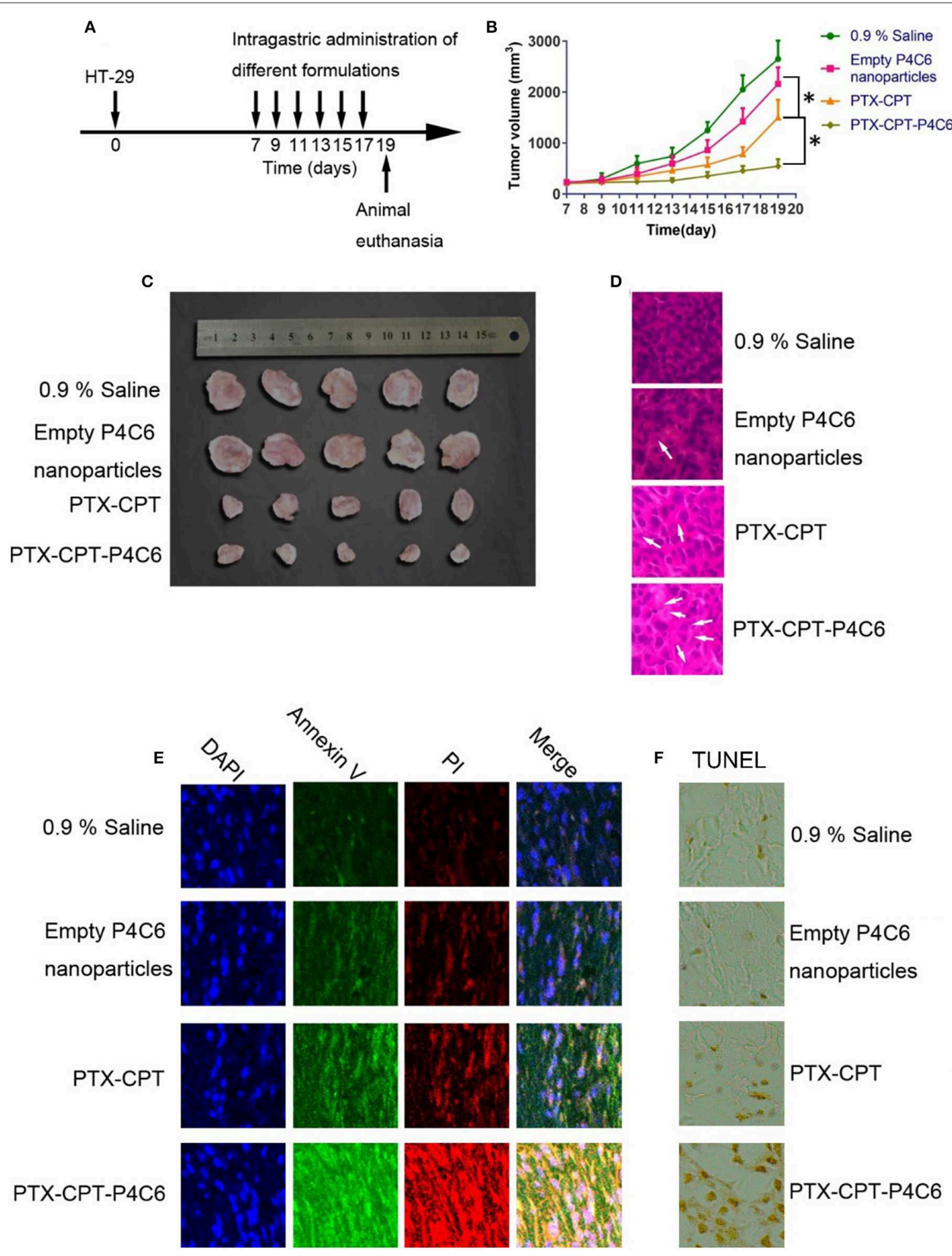

FIGURE 8 | Anti-tumor effects of different formulations in vivo. (A) Schematic diagram showing the HT-29 xenograft model and the timing of drug administration. (B) Tumor growth during treatment with empty P4C6 nanoparticles, PTX-CPT and PTX-CPT-P4C6. Negative control cells were treated with 0.9\% saline. (C) Photographs of excised HT-29 tumors removed on day 19. (D) Hematoxylin-eosin staining of tumor tissues removed on day 19. Magnification, $\times 400$. Arrows indicate shrunken or fragmented nuclei. (E) Staining of tumor tissue on day 19 to detect early apoptosis (annexin V) and late apoptosis (propidium iodide, PI). (F) Immunohistochemical analysis of the degree of apoptosis in tumor tissues by TUNEL staining. Magnification, $\times 400$. All results are from three independent experiments. Values are mean \pm SD. ${ }^{*} p<0.05$ (Student's $t$-test). 
A

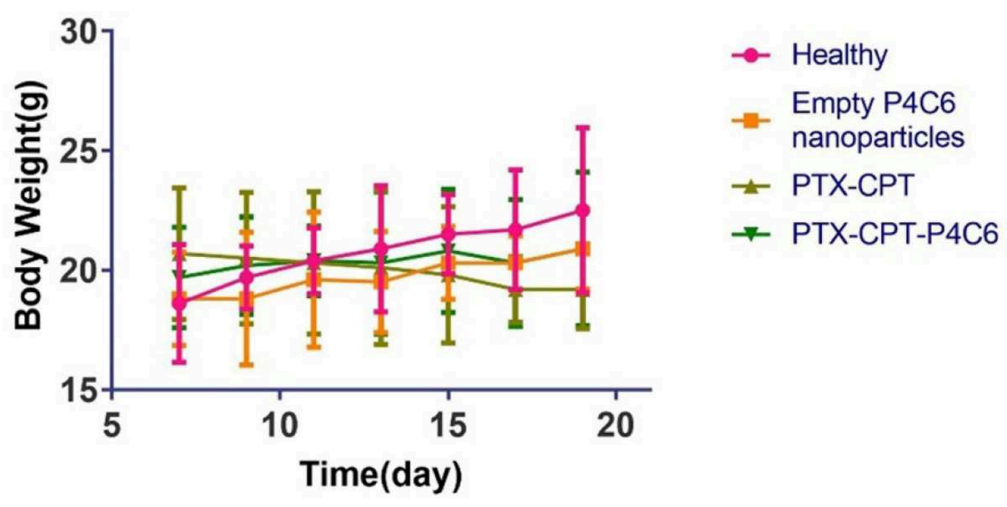

B

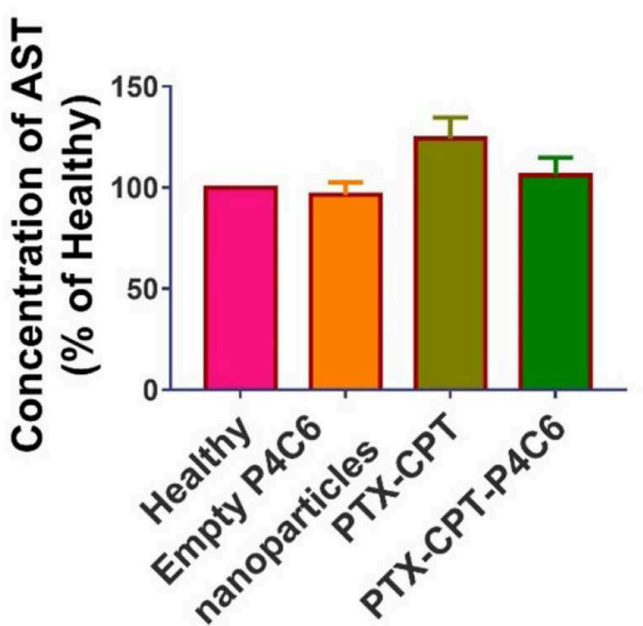

C

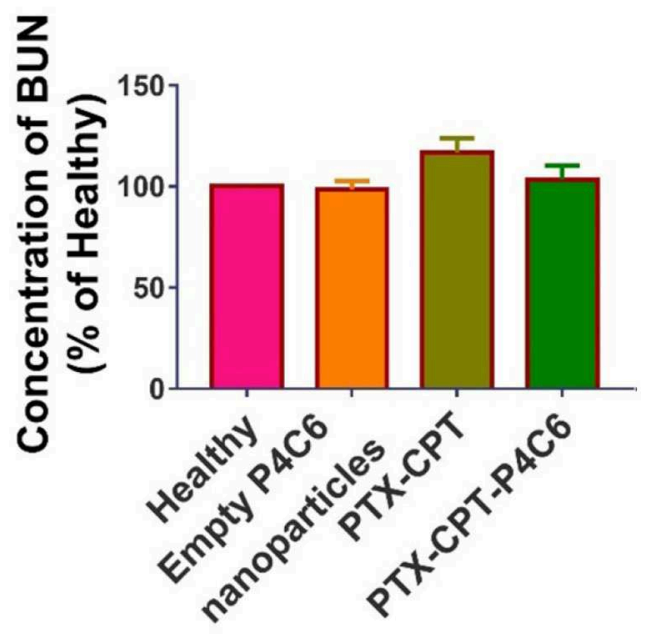

Kidney
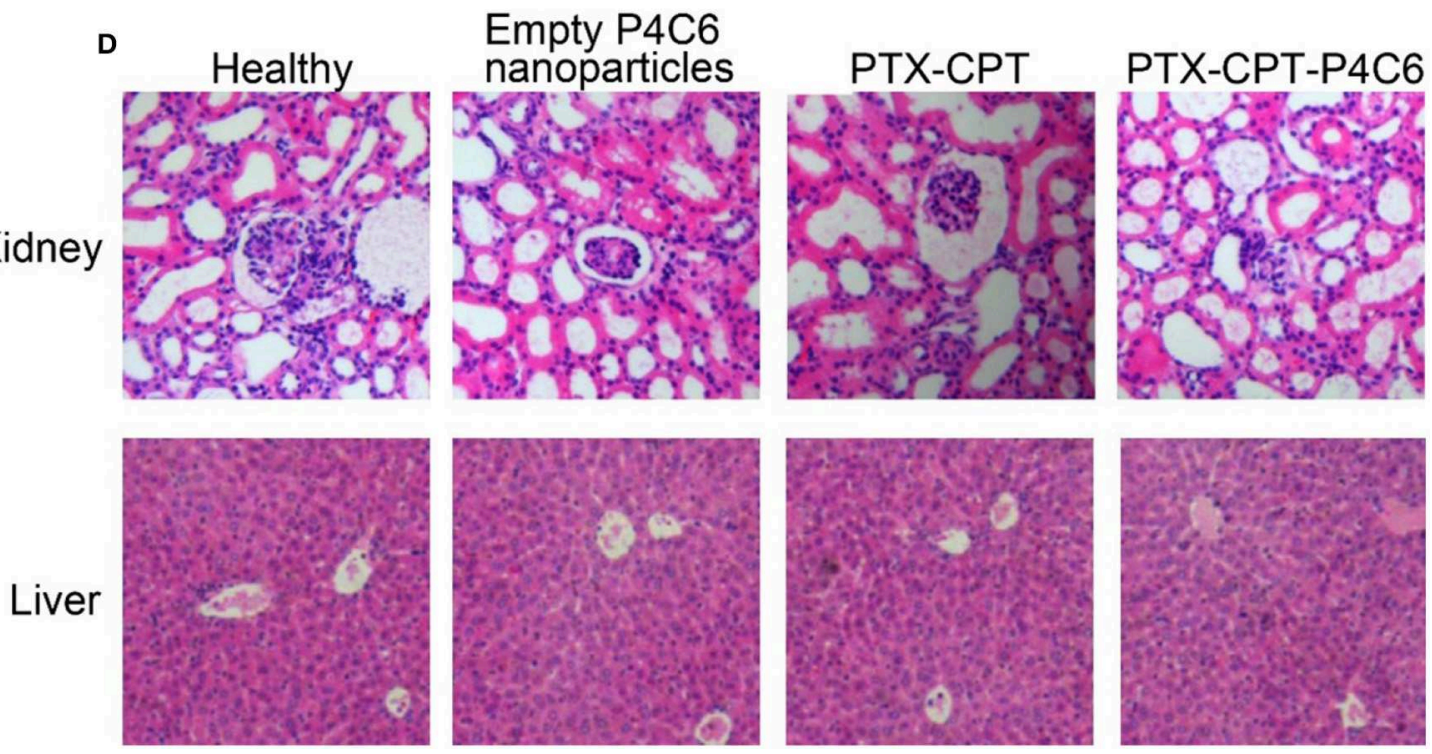

FIGURE 9 | Preliminary toxicity evaluation of PTX-CPT-P4C6 in vivo. Assays were performed after $12 \mathrm{~d}$ of treatment. (A) Body weight during treatments. (B,C) Levels of aspartate aminotransferase (AST) and blood urea nitrogen (BUN). (D) Hematoxylin-eosin staining of kidney and liver sections. Magnification, $\times 200$. 
(Al-Saffar et al., 2018; Guerrero et al., 2018; Liu et al., 2018) and can form well-differentiated adenocarcinoma consistent with primary colon cancer in nude mice (Handali et al., 2018). We found PTX-CPT-P4C6 nanovesicles to suppress proliferation of HT-29 cells more than Caco- 2 cells. The reasons and implications of this require further investigation.

Calixarenes are formed by the reaction of para-substituted phenol with formaldehyde. Calixarenes are aromatic macrocyclic compounds, which can form host-guest complexes with different small molecules after macrocyclic modification (Mo et al., 2015). The host-guest complexes formed between various calixarene derivatives and quaternary ammonium compound (such as trimethyllysine) have been well studied (Georghiou et al., 2018; Buldenko et al., 2019; Xu et al., 2019). Daze et al. found that p-sulfonated calix[4]arenes can specifically bind trimethylated lysine of different amino acids, non-methylated lysine and trimethylated lysine (Daze et al., 2012). The binding of cationic proteins or polypeptides with these host macrocyclic molecules is quite common (Adhikari et al., 2014; Cinà et al., 2017). Allen's group found that the affinity of p-sulfonated calix[4]arenes with $\mathrm{H} 3 \mathrm{~K} 9 \mathrm{Me} 3$ was significantly higher than that of $\mathrm{H} 3 \mathrm{~K} 9 \mathrm{Me} 0$ (Allen et al., 2014).

Our lab has been engaging in research on the use of phosphonated calix[4]arenes as carrier to improve the anticancer efficacy. In previous study, we found that P4C6 had a suitable size of cavity to accommodate cationic drug carboplatin to form host-guest complex. Then the amphiphilic phosphonated calix[4]arenes were obtained by properly modifying the lower rim of phosphonated calix[4]arenes with n-alkyl groups. The resultant drug-loaded vesicles can improve carboplatin accumulation within the tumor site. In another project, we loaded curcumin by P4C6 to form a core-shell structure micelle. Compared with free curcumin, the drug-loaded micelles can significantly reduce the number of $\mathrm{CD} 44^{+} / \mathrm{CD} 133^{+}$cancer stem cells in triple-negative breast cancer mice model. The mechanism was that drug-loaded micelles can reduce the expression of $\beta$-catenin in the nucleus. In the third study, we found, compared to free drugs, drugs loaded P4C6 showed stronger apoptosis induction as well as invasion and self-renewal capacity suppression in human ovarian cancer SKOV-3 cells. It was further found that the molecular mechanism of the above drugs-loaded nanoparticles may be through preventing JMJD3 (epigenetic regulator) binding with $\mathrm{H} 3 \mathrm{~K} 27 \mathrm{me} 3$ (suppressor of transcription), thereby protecting the lysine trimethylation of H3K27me3 and antagonizing the effect of JMJD3, finally promoting the differentiation of ovarian cancer stem cells by reducing the transcription of the oncogene HER2. Through the above researches, we found that P4C6 loaded with different anticancer drugs can produce synergistic effect. P4C6 seems to be able to downregulated JMJD3 expression to modulate the H3K27me3 epigenetic mark of the promoters of HER2 and MYCN.

\section{CONCLUSION}

The present study describes a new phosphonic acid calixarene derivative consisting of a single amphiphilic compound, P4C6, which can encapsulate CPT in the calixarene cavity and PTX among the hexane tails. The optimized PTX-CPTP4C6 nano-formulation shows efficient drug loading, small size, and low polydispersity. The nanoparticles were taken up efficiently by two colon cancer cell lines and showed greater cytotoxicity than a simple mixture of the two drugs. This cytotoxicity was associated with apoptosis induction, cell cycle arrest and suppression of invasion and migration. PTX-CPT-P4C6 inhibited HT-29 adenocarcinoma cells, which represent the most common form of colon cancer. PTXCPT-P4C6 showed the greatest inhibition of HT-29 tumors in mice, with negligible side effects. Therefore, the PTXCPT-P4C6 nano-formulation holds promise for improving the efficacy of PTX and CPT combination therapy against colon cancer.

\section{DATA AVAILABILITY STATEMENT}

The raw data supporting the conclusions of this manuscript will be made available by the authors, without undue reservation, to any qualified researcher.

\section{ETHICS STATEMENT}

The animal study was reviewed and approved by approved by the Ethics Committee of Guilin Medical University (Ethics number YXLL-2016-088).

\section{AUTHOR CONTRIBUTIONS}

$\mathrm{MeL}$ carried out biological experiments. $\mathrm{MC}$ and $\mathrm{MiL}$ synthesized and characterized nanomaterials. KW performed drug loading and releasing trials. LM analyzed data and review the manuscript. JM wrote the paper and led the research.

\section{FUNDING}

This work was supported by the National Natural Science Foundation of China (81860629), the Open Funds of the Guangxi Key Laboratory of Tumor Immunology and Microenvironmental Regulation (2018KF003), and Project for Promoting Scientific Research Ability of Staff in The Affiliated Hospital of Guilin Medical University (2018glmcy034).

\section{ACKNOWLEDGMENTS}

The authors thank the Analytical Centre at the Guilin Medical University.

\section{SUPPLEMENTARY MATERIAL}

The Supplementary Material for this article can be found online at: https://www.frontiersin.org/articles/10.3389/fbioe. 2019.00238/full\#supplementary-material 


\section{REFERENCES}

Adhikari, B. B., Fujii, A., and Schramm, M. P. (2014). Calixarene-mediated liquidmembrane transport of choline conjugates. Eur. J. Org. Chem. 2014, 2972-2979. doi: 10.1002/ejoc.201400025

Allen, H. F., Daze, K. D., Shimbo, T., Lai, A., Musselman, C. A., Sims, J. K., et al. (2014). Inhibition of histone binding by supramolecular hosts. Biochem. J. 459, 505-512. doi: 10.1042/BJ20140145

Alliot, J., Theodorou, I., Nguyen, D. V., Forier, C., Ducongé, F., Gravel, E., et al. (2019). Tumor targeted micellar nanocarriers assembled from epipodophyllotoxin-based amphiphiles. Nanoscale 11, 9756-9759. doi: 10.1039/C9NR01068H

Al-Saffar, N. M. S., Troy, H., Wong Te Fong, A. C., Paravati, R., Jackson, L. E., Gowan, S., et al. (2018). Metabolic biomarkers of response to the AKT inhibitor MK-2206 in pre-clinical models of human colorectal and prostate carcinoma. Br. J. Cancer 119, 1118-1128. doi: 10.1038/s41416-018-0242-3

Arena, G., Contino, A., Gulino, F. G., Magri, A., Sciotto, D., and Ungaro, R. (2000). Complexation of small neutral organic molecules by water soluble calix[4]arenes. Tetrahedron Lett. 41, 9327-9330. doi: 10.1016/S0040-4039(00)01687-7

Barcelos, F. C., de Matos, G. C., da Silva, M. J. S., da Silva, F. A. B., and Lima, E. D. C. (2019). Suspected adverse drug reactions related to breast cancer chemotherapy: disproportionality analysis of the brazilian spontaneous reporting system. Front. Pharmacol. 10:498. doi: 10.3389/fphar.2019.00498

Basu, S., Gavert, N., Brabletz, T., and Ben-Ze'ev, A. (2018). The intestinal stem cell regulating gene ASCL2 is required for L1-mediated colon cancer progression. Cancer Lett. 424, 9-18. doi: 10.1016/j.canlet.2018.03.022

Beloqui, A., des Rieux, A., and Preat, V. (2016). Mechanisms of transport of polymeric and lipidic nanoparticles across the intestinal barrier. Adv. Drug Deliv. Rev. 106, 242-255. doi: 10.1016/j.addr.2016.04.014

Bhatt, H., Kiran Rompicharla, S. V., and Ghosh, B. (2019). $\alpha$-tocopherol succinate-anchored PEGylated Poly(amidoamine) dendrimer for the delivery of paclitaxel: assessment of in vitro and in vivo therapeutic efficacy. Mol. Pharm. 16, 1541-1554. doi: 10.1021/acs.molpharmaceut.8b01232

Blind, N., Strigard, K., Gunnarsson, U., and Brannstrom, F. (2018). Distance to hospital is not a risk factor for emergency colon cancer surgery. Int. J. Colorectal Dis. 33 1195-1200. doi: 10.1007/s00384-018-3074-y

Bressand, D., Novell, A., Girault, A., Raoul, W., Fromont-Hankard, G., and Escoffre, J. M. (2019). Enhancing Nab-paclitaxel delivery using microbubbleassisted ultrasound in a pancreatic cancer model. Mol. Pharm. 16, 3814-3822. doi: 10.1021/acs.molpharmaceut.9b00416

Buldenko, V. M., Trush, V. V., Kobzar, O. L., Drapailo, A. B., Kalchenko, V. I., and Vovk, A. I. (2019). Calixarene-based phosphinic acids as inhibitors of protein tyrosine phosphatases. Bioorg. Med. Chem. Lett. 29, 797-801. doi: $10.1016 /$ j.bmcl.2019.01.026

Chen, W., Li, L., Zhang, X., Liang, Y., Pu, Z., Wang, L., et al. (2017). Curcumin: a calixarene derivative micelle potentiates anti-breast cancer stem cells effects in xenografted, triple-negative breast cancer mouse models. Drug Deliv. 24, 1470-1481. doi: 10.1080/10717544.2017.1381198

Cinà, V., Russo, M., Lazzara, G., Chillura Martino, D., and Lo Meo, P. (2017). Pre- and post-modification of mixed cyclodextrin-calixarene copolymers: a route towards tunability. Carbohydr. Polym. 157, 1393-1403. doi: $10.1016 /$ j.carbpol.2016.11.018

Dasari, S., and Tchounwou, P. B. (2014). Cisplatin in cancer therapy: molecular mechanisms of action. Eur. J. Pharmacol. 740, 364-378. doi: 10.1016/j.ejphar.2014.07.025

Daze, K. D., Pinter, T., Beshara, C. S., Ibraheem, A., Minaker, S. A., Ma, M. C. F., et al. (2012). Supramolecular hosts that recognize methyllysines and disrupt the interaction between a modified histone tail and its epigenetic reader protein. Chem. Sci. 3, 2695-2699. doi: 10.1039/c2sc20583a

Dehghan Kelishady, P., Saadat, E., Ravar, F., Akbari, H., and Dorkoosh, F. (2014). Pluronic F127 polymeric micelles for co-delivery of paclitaxel and lapatinib against metastatic breast cancer: preparation, optimization and in vitro evaluation. Pharm. Dev. Technol. 20, 1009-1017. doi: $10.3109 / 10837450.2014 .965323$

den Bakker, C. M., Schaafsma, F. G., Huirne, J. A. F., Consten, E. C. J., Stockmann, H. B. A. C., Rodenburg, C. J., et al. (2018). Cancer survivors' needs during various treatment phases after multimodal treatment for colon cancer - is there a role for eHealth? BMC Cancer 18:1207. doi: 10.1186/s12885-018-5105-z

Devarajan, P. V., Jindal, A. B., Patil, R. R., Mulla, F., Gaikwad, R. V., and Samad, A. (2010). Particle shape: a new design parameter for passive targeting in splenotropic drug delivery. J. Pharm. Sci. 99, 2576-2581. doi: 10.1002/jps.22052

Ellens, H., Meng, Z., Le Marchand, S. J., and Bentz, J. (2018). Mechanistic kinetic modeling generates system-independent P-glycoprotein mediated transport elementary rate constants for inhibition and, in combination with 3D SIM microscopy, elucidates the importance of microvilli morphology on Pglycoprotein mediated efflux activity. Expert Opin. Drug Metab. Toxicol. 14, 571-584. doi: 10.1080/17425255.2018.1480720

Georghiou, P. E., Rahman, S., Alodhayb, A., Nishimura, H., Lee, J., Wakamiya, A., et al. (2018). Calixazulenes: azulene-based calixarene analogues - an overview and recent supramolecular complexation studies. Beilstein J. Org. Chem. 14, 2488-2494. doi: 10.3762/bjoc.14.225

Gibaud, S., and Attivi, D. (2012). Microemulsions for oral administration and their therapeutic applications. Expert Opin. Drug Deliv. 9, 937-951. doi: 10.1517/17425247.2012.694865

Graham, U. M., Jacobs, G., Yokel, R. A., Davis, B. H., Dozier, A. K., Birch, M. E., et al. (2017). From dose to response: in vivo nanoparticle processing and potential toxicity. Adv. Exp. Med. Biol. 947, 71-100. doi: 10.1007/978-3-319-47754-1_4

Guerrero, S., Inostroza-Riquelme, M., Contreras-Orellana, P., Diaz-Garcia, V., Lara, P., Vivanco-Palma, A., et al. (2018). Curcumin-loaded nanoemulsion: a new safe and effective formulation to prevent tumor reincidence and metastasis. Nanoscale 10, 22612-22622. doi: 10.1039/C8NR06173D

Handali, S., Moghimipour, E., Rezaei, M., Ramezani, Z., Kouchak, M., Amini, M., et al. (2018). A novel 5-Fluorouracil targeted delivery to colon cancer using folic acid conjugated liposomes. Biomed. Pharmacother. 108, 1259-1273. doi: 10.1016/j.biopha.2018.09.128

Huschka, R., Barhoumi, A., Liu, Q., Roth, J. A., Ji, L., and Halas, N. J. (2012). Gene silencing by gold nanoshell-mediated delivery and laser-triggered release of antisense oligonucleotide and siRNA. ACS Nano 6, 7681-7691. doi: 10.1021/nn301135w

Karolczak-Bayatti, M., Forbes, K., Horn, J., Teesalu, T., Harris, L. K., Westwood, M., et al. (2019). IGF signalling and endocytosis in the human villous placenta in early pregnancy as revealed by comparing quantum dot conjugates with a soluble ligand. Nanoscale 11, 12285-12295. doi: 10.1039/C8NR10337B

Li, C., and Wallace, S. (2008). Polymer-drug conjugates: recent development in clinical oncology. Adv. Drug Deliv. Rev. 60, 886-898. doi: 10.1016/j.addr.2007.11.009

Li, H., Yan, L.,Tang, K. Y., Zhang, Z., Chen, W., Liu, G., and Mo, J. (2019). Synthesis of TPGS/curcumin nanoparticles by thin-film hydration and evaluation of their anti-colon cancer efficacy in vitro and in vivo. Front. Pharmacol. 10:769. doi: $10.3389 /$ fphar.2019.00769

Liu, X., Lukowski, J. K., Flinders, C., Georgiadis, R. A., Kim, S., Mumenthaler, S. M., et al. (2018). MALDI-MSI of immunotherapy: mapping the EGFRtargeting antibody cetuximab in 3D colon cancer cell cultures. Anal. Chem. 90, 14156-14164. doi: 10.1021/acs.analchem.8b02151

Mo, J., Eggers, P. K., Chen, X., Ahamed, M. R. Becker, T., Yong Lim, L., et al. (2015). Shear induced carboplatin binding within the cavity of a phospholipid mimic for increased anticancer efficacy. Sci. Rep. 5:10414. doi: 10.1038/srep10414

Mo, J., Eggers, P. K., Raston, C. L., and Lim, L. Y. (2014). Development and validation of a LC/TOF MS method for the determination of carboplatin and paclitaxel in nanovesicles. Anal. Bioanal. Chem. 406, 2659-2667. doi: $10.1007 / \mathrm{s} 00216-014-7684-0$

Mo, J., Eggers, P. K., Yuan, Z.-X., Raston, C. L., and Lim, L. Y. (2016). Paclitaxelloaded phosphonated calixarene nanovesicles as a modular drug delivery platform. Sci. Rep. 6:23489. doi: 10.1038/srep23489

Mo, J., Wang, L., Huang, X., Lu, B., Zou, C., Wei, L., et al. (2017). Multifunctional nanoparticles for co-delivery of paclitaxel and carboplatin against ovarian cancer by inactivating the JMJD3-HER2 axis. Nanoscale 9, 13142-13152. doi: 10.1039/C7NR04473A

Modi, D. A., Sunoqrot, S., Bugno, J., Lantvit, D. D., Hong, S., and Burdette, J. E. (2014). Targeting of follicle stimulating hormone peptideconjugated dendrimers to ovarian cancer cells. Nanoscale 6, 2812-2820. doi: $10.1039 / C 3 N R 05042 \mathrm{D}$ 
Ngandeu Neubi, G. M., Opoku-Damoah, Y., Gu, X., Han, Y., Zhou, J., and Ding, Y. (2018). Bio-inspired drug delivery systems: an emerging platform for targeted cancer therapy. Biomater. Sci. 6, 958-973. doi: 10.1039/C8BM00175H

Nogales, E., and Wang, H. W. (2006). Structural mechanisms underlying nucleotide-dependent self-assembly of tubulin and its relatives. Curr. Opin. Struct. Biol. 16, 221-229. doi: 10.1016/j.sbi.2006.03.005

Nunes, S. C., Ramos, C., Lopes-Coelho, F., Sequeira, C. O., Silva, F., GouveiaFernandes, S., et al. (2018). Cysteine allows ovarian cancer cells to adapt to hypoxia and to escape from carboplatin cytotoxicity. Sci. Rep. 8:9513. doi: 10.1038/s41598-018-27753-y

Paasonen, L., Sipilä, T., Subrizi, A., Laurinmäki, P., Butcher, S. J., Rappolt, M., et al. (2010). Gold-embedded photosensitive liposomes for drug delivery: triggering mechanism and intracellular release. J. Control. Release 147, 136-143. doi: 10.1016/j.jconrel.2010.07.095

Rabik, C. A., and Dolan, M. E. (2007). Molecular mechanisms of resistance and toxicity associated with platinating agents. Cancer Treat. Rev. 33, 9-23. doi: 10.1016/j.ctrv.2006.09.006

Robella, M., Vaira, M., Argenziano, M., Spagnolo, R., Cavalli, R., Borsano, A., et al. (2019). Exploring the use of pegylated liposomal doxorubicin (Caelyx $((\mathrm{R})))$ as pressurized intraperitoneal aerosol chemotherapy. Front. Pharmacol. 10:669. doi: 10.3389/fphar.2019.00669

Russo, L., Sánchez-Purrà, M., Rodriguez-Quijada, C., Leonardo, B. M., Puntes, V., and Hamad-Schifferli, K. (2019). Detection of resistance protein A (MxA) in paper-based immunoassays with surface enhanced Raman spectroscopy with AuAg nanoshells. Nanoscale 11, 10819-10827. doi: 10.1039/C9NR 02397F

Schreck, K., and Melzig, M. F. (2018). Intestinal saturated long-chain fatty acid, glucose and fructose transporters and their inhibition by natural plant extracts in Caco-2 cells. Molecules 23:E2544. doi: 10.3390/molecules23102544

Shah, A., and Dobrovolskaia, M. A. (2018). Immunological effects of iron oxide nanoparticles and iron-based complex drug formulations: therapeutic benefits, toxicity, mechanistic insights, and translational considerations. Nanomedicine 14, 977-990. doi: 10.1016/j.nano.2018.01.014

Shen, Z., and Ye, H. (2019). Interplay between ligand mobility and nanoparticle geometry during cellular uptake of PEGylated liposomes and bicelles. Nanoscale. 11:15971-15983. doi: 10.1039/C9NR02408E

Thibault, B., Genre, L., Le Naour, A., Broca, C., Mery, E., Vuagniaux, G., et al. (2018). DEBIO 1143, an IAP inhibitor, reverses carboplatin resistance in ovarian cancer cells and triggers apoptotic or necroptotic cell death. Sci. Rep. 8:17862. doi: 10.1038/s41598-018-35860-Z

Tourell, M. C., Shokoohmand, A., Landgraf, M., Holzapfel, N. P., Poh, P. S., Loessner, D., et al. (2017). The distribution of the apparent diffusion coefficient as an indicator of the response to chemotherapeutics in ovarian tumour xenografts. Sci. Rep. 7:42905. doi: 10.1038/srep42905

Wei, L., Wang, C., Chen, X., Yang, B., Shi, K., Benington, L. R., et al. (2019). Dual-responsive, methotrexate-loaded, ascorbic acid-derived micelles exert anti-tumor and anti-metastatic effects by inhibiting NF-kB signaling in an orthotopic mouse model of human choriocarcinoma. Theranostics 9, 4354-4374. doi: 10.7150/thno.35125

Xu, Z., Jia, S., Wang, W., Yuan, Z., Jan Ravoo, B., and Guo, D. S. (2019). Heteromultivalent peptide recognition by co-assembly of cyclodextrin and calixarene amphiphiles enables inhibition of amyloid fibrillation. Nat. Chem. 11, 86-93. doi: 10.1038/s41557-018-0164-y

Yang, Q., Yang, Y., Li, L., Sun, W., Zhu, X., and Huang, Y. (2015). Polymeric nanomedicine for tumor-targeted combination therapy to elicit synergistic genotoxicity against prostate cancer. ACS Appl. Mater. Interfaces 7, 6661-6673. doi: 10.1021/am509204u

Yodkeeree, S., Sung, B., Limtrakul, P., and Aggarwal, B. B. (2009). Zerumbone enhances TRAIL-induced apoptosis through the induction of death receptors in human colon cancer cells: evidence for an essential role of reactive oxygen species. Cancer Res. 69, 6581-6589. doi: 10.1158/0008-5472.CAN-09-1161

Yueh, A. E., Payne, S. N., Leystra, A. A., Van De Hey, D. R., Foley, T. M., Pasch, C. A., et al. (2016). Colon cancer tumorigenesis initiated by the H1047R mutant PI3K. PLoS ONE 11:e0148730. doi: 10.1371/journal.pone.0148730

Zhang, Q., Zhang, F., Li, S., Liu, R., Jin, T., Dou, Y., et al. (2019). A multifunctional nanotherapy for targeted treatment of colon cancer by simultaneously regulating tumor microenvironment. Theranostics 9 , 3732-3753. doi: 10.7150/thno.34377

Zhang, W., Li, C., Shen, C., Liu, Y., Zhao, X., Liu, Y., et al. (2016) Prodrug-based nano-drug delivery system for co-encapsulate paclitaxel and carboplatin for lung cancer treatment. Drug Deliv. 23, 2575-2580. doi: 10.3109/10717544.2015.1035466

Zhang, X., Qi, Z., Yin, H., and Yang, G. (2019). Interaction between p53 and Ras signaling controls cisplatin resistance via HDAC4- and HIF-1alphamediated regulation of apoptosis and autophagy. Theranostics 9, 1096-1114. doi: $10.7150 /$ thno. 29673

Zhao, X., Li, X., Zhao, Y., Cheng, Y., Yang, Y., Fang, Z., et al. (2017). Immune activities of polycationic vectors for gene delivery. Front. Pharmacol. 8:510. doi: 10.3389/fphar.2017.00510

Zhu, Y., Zhang, M., Luo, L., Gill, M. R., De Pace, C., Battaglia, G., et al. (2019). NFkappaB hijacking theranostic $\mathrm{Pt}(\mathrm{ll})$ complex in cancer therapy. Theranostics 9 , 2158-2166. doi: 10.7150/thno.30886

Conflict of Interest: The authors declare that the research was conducted in the absence of any commercial or financial relationships that could be construed as a potential conflict of interest.

Copyright (c) $2019 \mathrm{Li}$, Mao, Chen, Li, Wang and Mo. This is an open-access article distributed under the terms of the Creative Commons Attribution License (CC BY). The use, distribution or reproduction in other forums is permitted, provided the original author(s) and the copyright owner(s) are credited and that the original publication in this journal is cited, in accordance with accepted academic practice. No use, distribution or reproduction is permitted which does not comply with these terms. 